\title{
A SITUAÇÃO DO PARTO DOMICILIAR NO BRASIL
}

\author{
Paula Fernanda Almeida de Menezes Enfermeira graduada pela Universidade do Estado da \\ Bahia, mestranda do Instituto de Saúde Coletiva da \\ Universidade Federal da Bahia
}

Sandra Dutra Cabral Portella

Enfermeira, mestre em Enfermagem pela Universidade Federal da Bahia. Professora Assistente do curso de Enfermagem da Universidade do Estado da Bahia

Tânia Christiane Ferreira Bispo

Enfermeira, doutora em Saúde Pública pelo Instituto de Saúde Coletiva da Universidade Federal da Bahia. Professora Adjunta do curso de Enfermagem da Universidade do Estado da Bahia

\begin{abstract}
Resumo
Trata-se de uma pesquisa bibliográfica, exploratória, de abordagem qualitativa, que tem por objetivo descrever a situação em que ocorrem os partos domiciliares no Brasil. Entre o século XVI e o século XVIII os partos eram realizados em casa, de maneira não intervencionista, assistidos por parteiras, que desenvolviam suas práticas com base em um saber empírico transmitido de geração a geração. Com o advento do capitalismo, a medicina adquiriu um papel relevante devido à necessidade de controle das forças produtivas, levando aumento do interesse médico pela reprodução, o que acarretou a incorporação da obstetrícia à medicina e, posteriormente, a um gradativo processo de medicalização e institucionalização do parto, sob a justificativa do suposto potencial patológico deste evento. Entretanto, apesar da hegemonia do modelo hospitalocêntrico-tecnocrático consolidado a partir do século XX, muitos vêm sendo os nichos de resistência que buscam humanizar o nascimento e resgatá-lo enquanto um evento fisiológico. Diante de uma realidade desanimadora e recorrente de violência institucional e de práticas e condições desumanizadas, o parto domiciliar vem se apresentando como opção para mulheres que buscam realizar um parto mais natural e independente das rotinas e normas das instituições hospitalares. Os resultados deste estudo são apresentados de forma dissertativo-discursiva, buscando localizar o parto domiciliar enquanto prática cultural de comunidades com dificuldades de acesso aos serviços de saúde e enquanto uma alternativa ao modelo institucional. Constatou-se que, sob a perspectiva socioeconômica, existem condições distintas que caracterizam a ocorrência do parto domiciliar no Brasil.
\end{abstract}

Palavras-chave: Parto domiciliar; Parto natural; Assistência ao parto.

\section{THE SITUATION OF CHILDBIRTHS AT HOME THAT OCCUR IN BRAZIL}

\begin{abstract}
This is a bibliographical study of analysis exploratory and qualitative, which aims to describe the situation of childbirths at home that occur in Brazil. Between the sixteenth and eighteenth century the childbirths were performed at home, and realized with non- interventionist, assisted by midwives, who were developing their practices based on an empirical knowledge transmited from generation to generation. With the advent of capitalism, medicine acquired a relevant position because the society need to control of the productive forces, causing increased interest by reproducing and this result in the incorporation of obstetric medicine and, subsequently, a gradual process of medicalization and institutionalization of childbirth, with the justification of the supposed potential of this pathological event. However, despite the hegemony of model hospital medical consolidated from the twentieth century, some groups of resistance have realized efforts to humanize the childbirth and rescue as a physiological event. Facing a grim reality and recurrent violence and institutional practices and conditions dehumanized, the childbirths at home has been presented as an
\end{abstract}


option for women want to realize a natural childbirth and independent of the routines of hospitals. The results of this study are presented dissertational-discursive, indentifying the childbirth like a cultural practice in communities with limited access to health services and as an alternative to the institutional model. It was found that according with socio-economic perspective, there are different conditions that characterize the occurrence of childbirth at home in Brazil.

Keywords: Childbirth at home; Natural childbirth; Birth care.

\title{
LA SITUACIÓN DEL PARTO DOMICILIAR NO BRASIL
}

\begin{abstract}
Resumen
Se trata de una investigación bibliográfica, exploratoria, de enfoque cualitativo, que tiene por objetivo describir la situación en que ocurren los partos domiciliares en el Brasil. Entre el siglo XVI y el siglo XVIII los partos eran realizados en casa, de forma no intervencionista, auxiliados por parteras, que desarrollaban sus prácticas teniendo como base un conocimiento empírico transmitido de generación a generación. Con la llegada del capitalismo, la medicina adquirió un papel relevante debido a la necesidad de control de las fuerzas productivas, generando el aumento del interés médico por la reproducción, lo que ocasionó la incorporación de la obstetricia a la medicina y, posteriormente, a un gradual proceso de medicalización e institucionalización del parto, teniendo como justificativa el supuesto potencial patológico de este evento. No obstante, a pesar de la hegemonía del modelo hospital céntricotecnocrático consolidado a partir del siglo XX, existen muchos grupos de resistencia que buscan humanizar el nacimiento e rescatarlo como un evento fisiológico. Delante de una realidad desalentadora y frecuente de violencia institucional y de prácticas y condiciones deshumanizadas, el parto domiciliar se presenta como opción para mujeres que buscan realizar un parto mas natural e independiente de las rutinas y normas de los hospitales. Los resultados de este estudio son presentados de forma descriptiva-discursiva, buscando localizar o parto domiciliar como práctica cultural de comunidades con dificultades de acceso a los servicios de salud y como una alternativa al modelo institucional. Se constató que, desde la perspectiva socioeconómica, existen condiciones distintas que caracterizan un parto domiciliar en el Brasil.
\end{abstract}

Palavras-clave: Parto domiciliar; Parto natural; Auxilio al parto.

\section{INTRODUÇÃO}

Nas ultimas décadas, as trágicas condições em que se realizam os partos no Brasil constituem fator de grande preocupação dos pesquisadores e defensores do Movimento pela Humanização da Assistência ao Parto. Neste cenário pouco animador, são frequentes a violência institucional e as ditas 'práticas e condições desumanizadas', que se materializam a partir do tratamento hostil, do excesso de intervenções, do uso indiscriminado de medicamentos indutores do trabalho de parto, ${ }^{(1)}$ do desrespeito à autonomia da parturiente, ${ }^{(2)}$ da falta de suporte psicoemocional e da inadequação da estrutura-física às necessidades de privacidade, conforto e apoio familiar, ${ }^{(3)}$ além das precárias condições de trabalho as quais os profissionais da saúde estão submetidos. ${ }^{(4)}$

De acordo com o Grupo de Estudos sobre Nascimento e Parto, ${ }^{(5)}$ a transição do domicílio para o hospital foi substancial para que o parto se transformasse em um evento alienado e 
desumanizado. Contudo, como afirma Souza, ${ }^{(6)}$ não foi uma simples "mudança de endereço", mas de um conjunto de valores e concepções, que tem consonância com o processo de medicalização consolidado no Brasil a partir da segunda metade do século XX. Assim, o arcabouço ideológico que sustenta a hegemonia do atual modelo biomédico ‘tecnocrático' e 'hospitalocêntrico, ${ }^{(7)}$ possui regras muito bem definidas que especificam o local, quem assiste e os comportamentos esperados, ${ }^{(8)}$ sob o argumento do parto enquanto um evento de risco, potencialmente patológico. Neste viés, o uso de técnicas e procedimentos de forma abusiva tornase uma forma de dominação, restringindo o parto à prática médica ao mesmo tempo em que desumaniza a atenção.

Referindo-se ao número excessivo de cesáreas realizadas no Brasil, Rattner ${ }^{(9)}$ afirma que este passou a ser o método 'normal' de parir, contribuindo para aumentar a morbimortalidade materna e perinatal, bem como para a elevação dos gastos desnecessários de recursos. ${ }^{(5)}$ Observase que se constituiu um processo de desnaturalização do parto, onde se subentende, no discurso biomédico, a incapacidade da mulher de parir. ${ }^{(10)}$

Diante desta realidade, o Ministério da Saúde, em consonância com a tendência dos principais organismos internacionais do setor saúde e dos movimentos de humanização, adotou como estratégia a implantação da Política Nacional de Humanização (PNH) que, no âmbito do parto e nascimento, tem confluência com o Programa de humanização do Pré-natal e Nascimento e com a Política Nacional de Atenção Integral à Saúde da Mulher, e se fundamenta na premissa de resgatar o parto enquanto um evento fisiológico e na devolução do protagonismo da mulher e do bebê, buscando promover um nascimento mais humano e digno. ${ }^{(11,12)}$

Sob a mesma premissa, alguns grupos de ativistas da humanização do parto e nascimento, em especial no âmbito da enfermagem obstétrica, vêm defendendo a possibilidade das mulheres darem à luz fora do ambiente hospitalar, ${ }^{(13)}$ justificando que 80 a $90 \%$ dos partos não apresenta complicações. ${ }^{(14)}$ Considera-se que estrutura física tem uma íntima relação com o modelo assistencial $^{(14)}$ e, portanto, o próprio espaço hospitalar acaba se configurando como um instrumento de submissão, a partir da aplicação de rotinas, normas e regras hierárquicas que, de acordo com o GENP, ${ }^{(5)}$ são entraves à humanização. Desta maneira, percebe-se que o local do parto não é apenas um cenário, pois influencia e condiciona as relações que se procedem. 
Assim, o parto domiciliar planejado vem se apresentando como opção para mulheres que buscam realizar um parto mais natural e independente das rotinas e normas das instituições hospitalares. ${ }^{(6)}$ Neste sentido, Nascimento et al $^{(15)}$ aponta que o país está passando por um período de transição do modelo de atenção e resgatando de valores que ultrapassam a ciência e a tecnologia. Souza ${ }^{(6)}$ afirma ainda que esse cenário agrega novos valores, comportamentos e sentimentos ao processo de nascer.

\section{DAS ‘COMADRES’ À INSTITUCIONALIZAÇÃO DO PARTO}

Durante séculos o parto foi um evento ritualístico cercado de experiências objetivas e subjetivas exclusivamente femininas, restrito a uma esfera privada e parte do cotidiano das famílias. ${ }^{(8,16) ~ " E m ~ q u a l q u e r ~ p a i ́ s ~ e ́ ~ p o s s i ́ v e l ~ i d e n t i f i c a r ~ o ~ p r o c e s s o ~ d o ~ p a r t o ~ a t r a v e ́ s ~ d o ~ t e m p o ~ c o m o ~}$ um ato de caráter feminino, manejado por ritos e tradições, impregnados pela fé e mistério."(17)

No Brasil, a formação da tradição do partejar coincide com a colonização, a partir das portuguesas, negras e caboclas velhas das camadas menos favorecidas da população. ${ }^{(17)}$

Em via de regra, entre o século XVI e o século XVIII os partos eram realizados em casa, de maneira não intervencionista, assistidos por mulheres também conhecidas como 'parteiras', 'comadres', ‘aparadeiras' e 'curiosas' - pessoas reconhecidas em suas comunidades, detentoras de um saber empírico transmitido de geração a geração a partir de uma transmissão oral e simbólica, em geral, realizada nas relações de parentesco, numa rede de relações femininas a qual se reservava o mistério do nascimento. ${ }^{(18,19)}$

Era conferida à pratica do parto uma íntima relação com a religiosidade e a natureza, com o uso de plantas, animais e minerais curativos, amuletos e talismãs, rezas e rituais, ${ }^{(20)}$ numa relação construída sob as bases da confiança e afetividade, favorecida pela autoridade tradicional das parteiras na comunidade e por reconhecidos valores subjetivos.

Com o advento do Capitalismo, houve um gradativo desenvolvimento da medicina moderna e social na Europa, que adquiriu um papel relevante devido à necessidade de controle das populações, levando ao aumento do interesse médico pela reprodução e acarretando a incorporação da obstetrícia à medicina, no século XVIII. ${ }^{(21)}$ Para Barreto, ${ }^{(18)}$ o argumento que sustentava essa incorporação tinha suas bases na concepção da gestação e do parto enquanto eventos patológicos (ou potencialmente patológicos), fundamentando a hegemonia da medicina, 
bem como fortalecendo a medicalização progressiva do corpo feminino.

O capitalismo, desenvolvendo-se em fins do século XVIII e início do século XIX, socializou um primeiro objeto que foi o corpo enquanto força de produção, força de trabalho. $\mathrm{O}$ controle da sociedade sobre os indivíduos não se opera simplesmente pela consciência ou pela ideologia, mas começa no corpo, com o corpo. ${ }^{(2)}$

No Brasil, esse processo começou a repercutir nas primeiras décadas do século XIX, a partir da vinda da Família Real, da fundação das Faculdades de Medicina da Bahia e do Rio de Janeiro, do licenciamento de parteiras e da criação dos cursos de partos. ${ }^{(23)}$ Nessa configuração, além das parteiras leigas, os médicos, parteiras examinadas, parteiras diplomadas [e posteriormente as enfermeiras] passaram a compor o cenário do parto. ${ }^{(18)}$

Até então, tanto partos normais quanto complicados eram realizados no domicílio, mesmo quando havia participação da figura masculina na assistência, sendo raros os encaminhamentos às Santas Casas, ${ }^{(24)}$ havendo uma grande resistência das mulheres e famílias quanto à inserção dos médicos na esfera da assistência à saúde da mulher e ao parto. Diante do pudor e da moral religiosa, as parteiras eram figuras de maior aceitação social, visto que, inseridas no universo dos valores femininos, poderiam compreender e compartilhar das intimidades e problemas das mulheres, como observa Weber, ${ }^{(25)}$ que afirma que 'ser parteira' era um símbolo de confiabilidade para a população. Como consequência, os médicos possuíam apenas conhecimentos teóricos de obstetrícia, pois não conseguiam adesão das mulheres para a realização do acompanhamento da gestação e parto nos hospitais, ${ }^{(26)}$ sendo convocados apenas em casos extremos, quando era necessária a intervenção cirúrgica.

Através da leitura de Mott ${ }^{(23)}$ podemos concluir que foi necessário que os médicos, além dos partos complicados, passassem a assistir aos partos normais para ganhar clientela, para dissociar a figura médica das situações de fatalidade e para ampliar as possibilidades de prática obstétrica. Conseguintemente, a introdução de instrumentos, como o fórceps, influenciou consideravelmente no processo aceitação da figura médica, ao transformar a obstetrícia em uma disciplina técnica e intelectual, bem como ao inserir a ideia o parto é potencialmente perigoso e acerca da possibilidade de comandar o nascimento. ${ }^{(27)}$ Neste contexto, o hospital seria o espaço que legitimaria o controle do corpo através da medicina. "O corpo é uma realidade biopolítica. A medicina é uma estratégia biopolítica". (22) 
A mudança para o hospital, portanto, significou a efetivação de um processo de dominação masculina e a retirada da protagonismo da mulher na esfera do parto. Uma expressão prática disto é a mudança da posição de parir, sendo adotada uma posição horizontal, para garantir o conforto do obstetra, em substituição às posições verticalizadas, que favorecem a mulher. ${ }^{(6)}$

Empreendeu-se, portanto, grande esforço para legitimar o saber e a prática médica e, sob a égide de discurso higienista e da competência técnica e intelectual masculina, deslegitimar as mulheres que detinham o saber informal da cura de doenças, do cuidado do corpo e da parturição. ${ }^{(26,27,28)}$ De acordo com estudos de Mott, ${ }^{(28)}$ na literatura médica, encontram-se muitas referências depreciativas às 'parteiras leigas' acerca da falta conhecimentos científicos e de práticas de higiene. A mesma autora lembra que, naquele período, nem mesmo os partos realizados por médicos eram seguros - fosse em residências, fosse em maternidades.

Segundo Acker ${ }^{(8)}$ citando Helman, ${ }^{(29)}$ o processo de institucionalização do parto, no Brasil, passou a predominar somente a partir de 1930, quando o número de partos hospitalares ultrapassou o de partos domiciliares. Mas Wolff e Waldow ${ }^{(30)}$ referem que a definição do parto enquanto um evento público (institucional) se deu principalmente após a Segunda Guerra Mundial, se conformando não apenas na transferência do local do parto do domicílio para as instituições hospitalares, mas significando a mudança de concepções de uma sociedade que passa a ver este evento privado, familiar e iminentemente fisiológico [o parto], sob uma óptica patológica e medicalizada que lançou bases para a adoção do modelo tecnocrático e intervencionista norte-americano, que predomina até os dias atuais. ${ }^{(31,32,33)}$

\section{RESISTINDO À MEDICALIZAÇÃO}

No Brasil, apesar da consolidação da medicalização e institucionalização do parto no século XX, muitos vêm sendo os nichos de resistência que buscam humanizar o nascimento e resgatá-lo enquanto um evento fisiológico. Segundo Souza, ${ }^{(6)}$ a intensificação da hospitalização e do intervencionismo no âmbito do parto já provocava debates no campo da saúde desde a década de 50, em especial a partir da difusão da ideia do 'Parto sem dor' na Europa, que propunha abolir 
a dor a partir da utilização de métodos não farmacológicos, como técnicas de respiração e relaxamento, com respeito à anatomia e fisiologia do parto.

$\mathrm{Na}$ crítica às tendências anti-humanistas na atenção à saúde, destacaram-se os movimentos contraculturais, sobretudo o movimento feminista, que, desde a década de 1960, já incorporava em sua pauta a humanização das praticas em saúde, em especial a saúde da mulher. ${ }^{(34)}$ No âmbito do parto e nascimento, criticavam frontalmente o número crescente de cesarianas e passaram a levantar a bandeira do parto natural, do parto domiciliar e da criação de casas de parto normal. ${ }^{(35,36)}$ Nos 'interstícios' desses movimentos, médicos e enfermeiras obstétricas passaram, então, a realizar partos domiciliares nas cidades. ${ }^{(6)}$

A partir da década de 70, evideciaram-se alguns pesquisadores que defendiam o desenvolvimento de práticas mais humanas e menos intervencionistas no parto. Na Europa destacaram-se Frederick Leboyer - que introduziu a ideia do recém-nascido sensível e da importância de proporcionar condições para que este evento fosse o menos traumático possível; ${ }^{(37)}$ e Michel Odent - que descreveu a fisiologia do parto e defendeu a importância do vínculo amoroso. ${ }^{(38)}$ No Brasil, Galba de Araújo foi um grande defensor da conciliação entre a ciência e a tradição e incentivador do treinamento de parteiras tradicionais, resultados de seus estudos no Nordeste. Outra importante figura no cenário brasileiro foi Moysés Paciornick, difusor do 'parto de cócoras' e causídico da valorização do saber tradicional, em especial das culturas indígenas. ${ }^{(39)}$

Na década de 80, a Organização Mundial da Saúde, criticou severamente a excessiva medicalização do parto $^{(35)}$ e lançou 'recomendações', desestimulando a utilização de procedimentos nocivos como tricotomia, enema, toques excessivos e exploração manual do útero - além de valorizar a presença do acompanhante e de estimular o vínculo afetivo mãe-bebê precoce. Ainda na década de 80, as ideias de "casal grávido" e de parto natural ganharam força no país, ${ }^{(6)}$ contraditoriamente ao mesmo tempo em que se fortalecia o modelo norte-americano de assistência. Entretanto, estas recomendações ainda hoje enfrentam forte resistência por parte das instituições hospitalares e dos profissionais de saúde. ${ }^{(6)}$

Nesse cenário, que incorporava o fortalecimento dos grupos de resistência à ditadura militar, a existência de um movimento mundial em prol da humanização do parto e do nascimento, a conquista de espaço no poder público brasileiro pelos movimentos de mulheres e, 
paralelamente, contribuições sobre a atenção integral à saúde da mulher no meio acadêmico, ${ }^{(27)}$ foi instituído o Programa de Assistência Integral à Saúde da Mulher (PAISM) em 1984. Tal programa foi importante na construção conceitual do processo de Reforma Sanitária, ${ }^{(40)}$ visto que trazia princípios e diretrizes que, alguns anos mais tarde, viriam a formar o arcabouço conceitual do Sistema Único de Saúde. ${ }^{(41)}$ Cabe destacar que, entre as suas diretrizes, encontrava-se

a adoção de medidas visando à melhoria da qualidade do parto domiciliar realizado pelas parteiras tradicionais, através do treinamento, supervisão, fornecimento de material de parto e estabelecimento de mecanismos de referência. ${ }^{(42)}$

Observa-se, portanto, que desde a década de 80 a parteira tradicional já constituía uma alternativa na assistência ao parto domiciliar nas zonas rurais ${ }^{(26)}$ e, como alerta Tornquisnt, ${ }^{(35)}$ este resgate - que teve continuidade com a criação do Programa Nacional de Parteiras Tradicionais, em 1991- tem consonância com as tendências neoliberais da OMS, através da redução dos custos dos serviços de saúde e da supressão de direitos sociais. Salienta-se, ainda, a forte legitimação da hierarquia de funções nas recomendações da OMS, onde as parteiras populares são transferidas de uma posição de prestigio e reconhecimento nas comunidades para uma condição subalterna na equipe de saúde.

No entanto, a figura da parteira ganha nova conotação no âmbito da humanização e do Programa Trabalhando com Parteiras Tradicionais, de 2000, existindo uma forte tendência de romantização das mesmas, na qual se tornam símbolos anacrônicos "de um passado ao qual não se pretende retornar", mas que ecoam na resistência à medicalização do parto, à mercantilização da saúde e à fragmentação do ser humano. ${ }^{(35)}$ E para além de uma construção simbólica, a valorização das parteiras tradicionais após longo período de exclusão revela o reconhecimento da insuficiência da cobertura da assistência à saúde no Brasil, sobretudo no Norte e Nordeste do país, onde os partos domiciliares ocorrem "de forma precária e em situação de exclusão e isolamento", desassistidos pelo SUS. ${ }^{(39)}$

Embora a medicalização do parto seja hegemônica e que os nichos de transformação pareçam poucos e pequenos, muitos dos ensejos de mudança tem se expressado na esfera de Estado nas ultimas décadas, com a criação de instrumentos legislativos e normativos, programas e políticas, a exemplo: 
- da regulamentação da realização de parto normal sem distócia e a emissão de laudo de internação por enfermeira obstetra, através da Portaria GM n.163/1998; ${ }^{(43)}$

- da instituição dos Centros de Parto Normal a partir da Portaria n. 888/1999 ${ }^{(44)}$ e a sua regulamentação através da Portaria GM n. 985/1999; ${ }^{(45)}$

- do incentivo à criação de cursos de Enfermagem Obstétrica, em 1999; ${ }^{(39)}$

- da determinação do teto percentual para o pagamento de cesáreas no SUS; ${ }^{(39)}$

- da possibilidade de pagamento de partos domiciliares a parteiras tradicionais por meio do PAB variável. ${ }^{(15)}$

Contudo, essas medidas vêm sendo sufocadas pelos gestores e pelas entidades coorporativas da medicina que, sob o argumento do parto com risco e potencialmente patológico, defendem a necessidade de controle e monitoração deste evento.

Atualmente, deposita-se na PNH grande esperança com relação à superação de problemas envolvidos na consolidação do SUS e na construção de novas práticas no setor saúde. Porém, deve-se considerar o desafio de qualificar a atenção em um sistema de saúde com valores, concepções e práticas que, por si só, contradizem a proposta humanística.

Nos debates atuais do ativismo da humanização, diversos questionamentos vêm sendo colocados em pauta, que apontam para a necessidade de rever a forma como vêm nascendo os seres humanos. A ReHuNa (Rede de Humanização do Nascimento), por exemplo, criada em 1993, é uma das organizações que surgiram no Brasil com o propósito de difundir discussões e práticas de modo a contribuir com a construção de uma assistência mais humana. ${ }^{(9)}$

Este é um momento em que o protagonismo da mulher e do bebê vem sendo intensamente discutido, surgindo conceitos como consentimento informado e plano de parto. ${ }^{(6)}$ É função de quem assiste ao parto oferecer subsídios para que os genitores possam participar ativamente de todo o processo.

A possibilidade de o parto considerado de baixo risco ocorrer fora do ambiente hospitalar é uma questão emergente levantada por profissionais de saúde, organizações, ativistas e leigos que possuem consonância com a pauta humanização do parto e nascimento. Assim, sob a perspectiva do parto enquanto um evento natural e fisiológico, e que o ambiente ideal para o nascimento é um local que ofereça segurança e viabilize uma assistência adequada à mãe e ao 
bebê, ${ }^{(13)}$ o parto domiciliar planejado vem se apresentando como opção para mulheres que buscam realizar um parto mais natural e independente das rotinas e normas das instituições hospitalares. ${ }^{(6)}$

Alguns autores, como Souza (2005), inclusive dicotomizam o parto domiciliar do parto hospitalar humanizado. Ela afirma que práticas ditas humanizadas, como, parto de cócoras, por exemplo, no ambiente hospitalar acabam por se transformar em rotinas, normatizando o parto e, portanto, retirando a autonomia da mulher. Compreende-se que mesmo em uma maternidade humanizada a privacidade, o conforto e o respeito à autonomia e liberdade da mulher não são qualitativamente comparáveis ao ambiente doméstico. ${ }^{(33)}$

Em um modelo mais compatível com a institucionalização, os Centros de Parto Normal são apontados como alternativa, pois simulam o ambiente doméstico e representam um estimulo à redução de cesáreas e à realização do parto vaginal. Porém, mesmo esta proposta encontra resistência na comunidade médica, ${ }^{(6)}$ apontando a existência de embates entre categorias profissionais, em meio à discussão de qual seria o profissional mais qualificado para assistir ao parto normal.

Diante da necessidade de construir novas práticas na atenção ao parto, e considerando o parto domiciliar enquanto pauta dos setores preocupados em proporcionar um nascimento mais humano e devolver o protagonismo da mulher e do bebê, este estudo teve como objetivo descrever a situação em que ocorrem os partos domiciliares no Brasil. Trata-se de uma revisão de literatura, exploratória, com análise qualitativa dos dados, desenvolvida a partir de material presente em dissertações e artigos científicos confiáveis publicados em bases de dados de bibliotecas virtuais no período de 2000 a 2010.

\section{MATERIAIS E MÉTODOS}

Trata-se de uma pesquisa bibliográfica, exploratória, com análise qualitativa dos dados, sobre a situação atual do parto domiciliar no Brasil.

A pesquisa bibliográfica foi desenvolvida a partir de material presente em livros, dissertações e artigos científicos confiáveis que diziam respeito ao assunto que se pretendia abordar, permitindo "a cobertura de uma gama de fenômenos muito mais ampla do que aquela 
que poderia pesquisar diretamente". ${ }^{(46)}$ Este tipo de pesquisa, no entanto, não se refere a uma mera repetição do que foi publicado até o momento, visto que possibilita olhar sob outra perspectiva o mesmo assunto, gerando novas conclusões e demandas. ${ }^{(47)}$

Considerando esta pesquisa de natureza exploratória, foi motivada por um acontecimento prévio que gerou interesse na investigação e procede-se a partir da identificação e descrição do objeto/fenômeno e dos fatores que se relacionam com o mesmo, averiguando suas origens, fundamentando as hipóteses e estabelecendo relações entre as variáveis. ${ }^{(46,48)}$

A coleta de dados foi realizada considerando o objetivo do estudo e amparada na hipótese de que, sob a perspectiva socioeconômica, existem condições distintas que caracterizam a ocorrência do parto domiciliar no Brasil.

Após a escolha da temática a ser abordada, a fase exploratória iniciou-se com uma pesquisa aleatória sobre o parto domiciliar no Brasil, que possibilitou uma maior familiaridade com o tema, bem como lançar indicativos de uma fundamentação teórico-ideológica. Esta familiarização contribuiu para ampliar as perspectivas sobre o assunto e para melhor delimitar o objetivo da pesquisa.

Em seguida, buscou-se artigos de revistas indexadas e dissertações nas bases de dados das bibliotecas virtuais Scielo (Scientific Eletronic Library Online), Google Acadêmico e BIREME (Biblioteca Regional de Medicina), utilizando como descritores: 'parto domiciliar' e 'parto em casa'. Inicialmente foram selecionados os trabalhos os quais apresentassem textos na íntegra em português, publicados de 2000 à 2010, com títulos ou resumos que indicavam uma aproximação com o tema deste estudo e que foram considerados pertinentes após uma leitura flutuante. Como não foram encontrados muitos trabalhos, realizou-se um resgate de alguns títulos presentes nas referencias bibliográficas dos estudos que já haviam sido selecionados, dando prosseguimento com a pesquisa direta nas mesmas bases de dados, em sites de busca e em bibliotecas.

Para a coleta de dados foi realizada uma leitura sistemática, interpretativa e criteriosa de todos os textos selecionados, na íntegra. A fim de catalogar os dados e informações obtidos, foram realizados fichamentos bibliográficos, por título e por assunto, como proposto por Minayo. ${ }^{(49)}$ A análise de dados foi realizada a partir de leituras e reflexões, articulando o referencial teórico aos dados encontrados, tendo como eixo norteador o objeto de pesquisa. Os resultados encontrados serão apresentados a seguir nas categorias Parto domiciliar como prática 
tradicional e Parto domiciliar como alternativa ao modelo institucional, de forma dissertativodiscursiva.

Não foi necessária a aprovação por um Comitê de Ética em Pesquisa por se tratar de uma pesquisa bibliográfica.

\section{PARTO DOMICILIAR NO BRASIL}

\section{ALGUMAS CONSIDERAÇÕES PRELIMINARES}

Nos quadros 1 e 2 seguem as matrizes dos títulos utilizados como fontes bibliográficas para esta pesquisa. Como pode ser observada, a categorização dos resultados coincidiu com a categorização dos trabalhos selecionados, o que facilitou a análise dos dados. Todos os trabalhos levantados possuem abordagem qualitativa, sendo a maioria enquadrada como pesquisa de campo; ${ }^{(17)}$ dos demais, 01 relato de experiência, 02 pesquisas bibliográficas e 01 documento do ministerial, totalizando 21 trabalhos. A escassez de artigos e teses com abordagem quantitativa deve ser mencionada, sugerindo tanto a maior afinidade da temática com a abordagem qualitativa, quanto as possíveis dificuldades no levantamento de dados quantitativos fidedignos.

Destaca-se que todos os trabalhos científicos que se enquadraram nos critérios metodológicos de inclusão deste estudo e em que foi possível a identificação da categoria profissional das pesquisadoras(es) - com exceção do documento do Ministério da Saúde - foram realizados por enfermeiras(os), indicando que atualmente a enfermagem é o setor que vem se preocupando com as pesquisas em torno do parto domiciliar no Brasil.

A categoria Parto domiciliar como prática tradicional reuniu os resultados e discussões acerca do parto domiciliar realizado por parteiras tradicionais (ou populares). Esclarece-se que o termo tradicional foi adotado em consonância com o conceito de Ferreira, ${ }^{(50)}$ em que a tradição poderia ser compreendida enquanto "conhecimento ou prática resultante de transmissão oral ou de hábitos inveterados" de "geração em geração". Sobre este tópico, foram encontrados estudos de todas as 5 regiões do Brasil, o que indica que a cultura tradicional da parturição possui nichos de sobrevivência mesmo em regiões com grande avanço institucional na saúde, como o Sul e o Sudeste. Contudo, destaca-se a região Norte como locus de pesquisa de parto domiciliar assistido 
por parteiras tradicionais, ainda que as algumas das publicações destes trabalhos tenham se dado em outras regiões.

No que se refere ao parto domiciliar realizado em zonas urbanas, foram encontrados apenas trabalhos realizados no Sul e Sudeste, em pouca quantidade. Sobre a escassez de pesquisas acerca esta temática pode-se sugerir algumas hipóteses: 1) que esta modalidade tenha uma maior ênfase nas regiões supracitadas; 2) que, considerando o fenômeno como emergente 
Quadro 1 - Trabalhos selecionados que se enquadraram na categoria de análise Parto domiciliar como prática tradicional

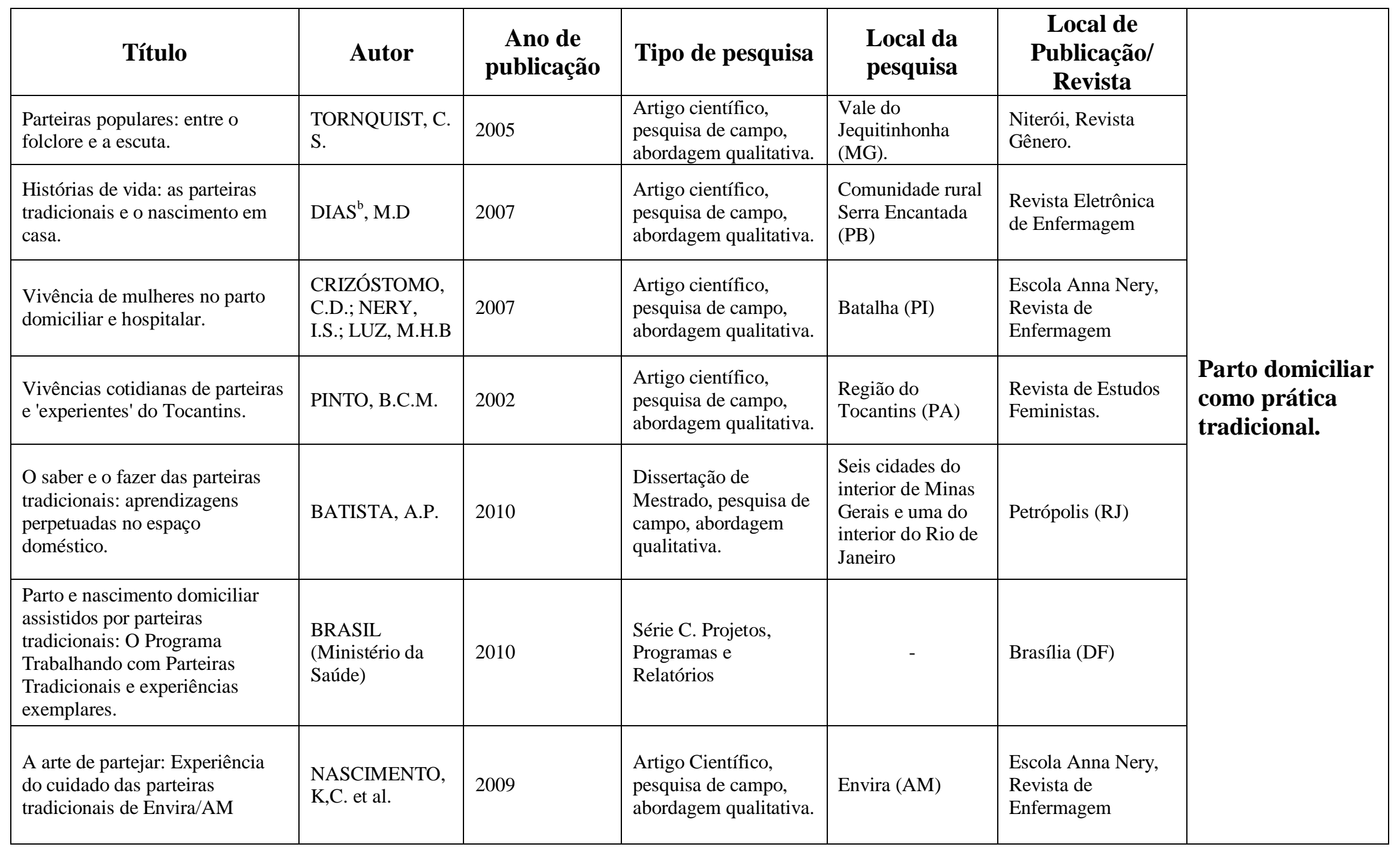




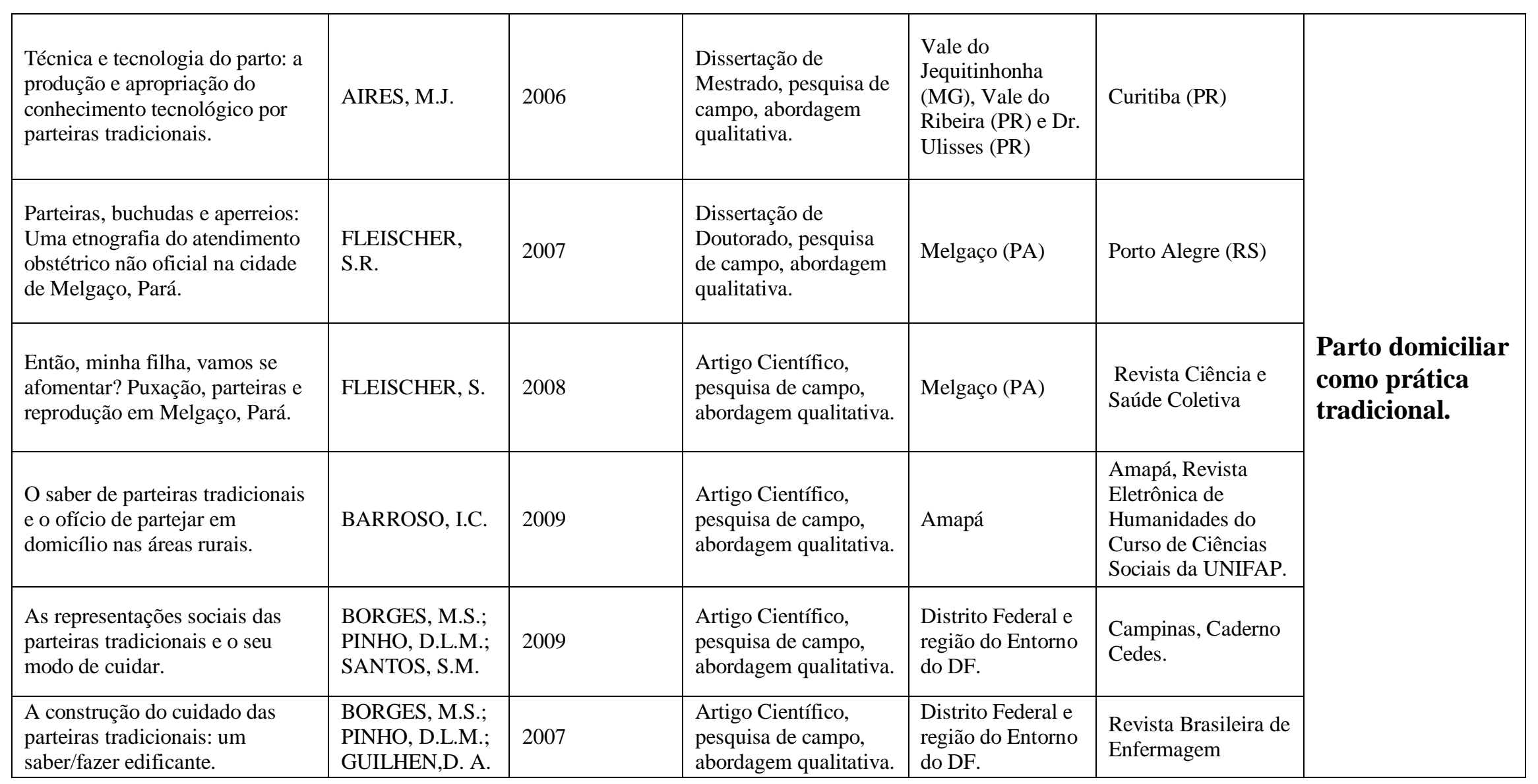


Quadro 2 - Trabalhos selecionados que se enquadraram na categoria de análise Parto domiciliar como alternativa ao modelo institucional

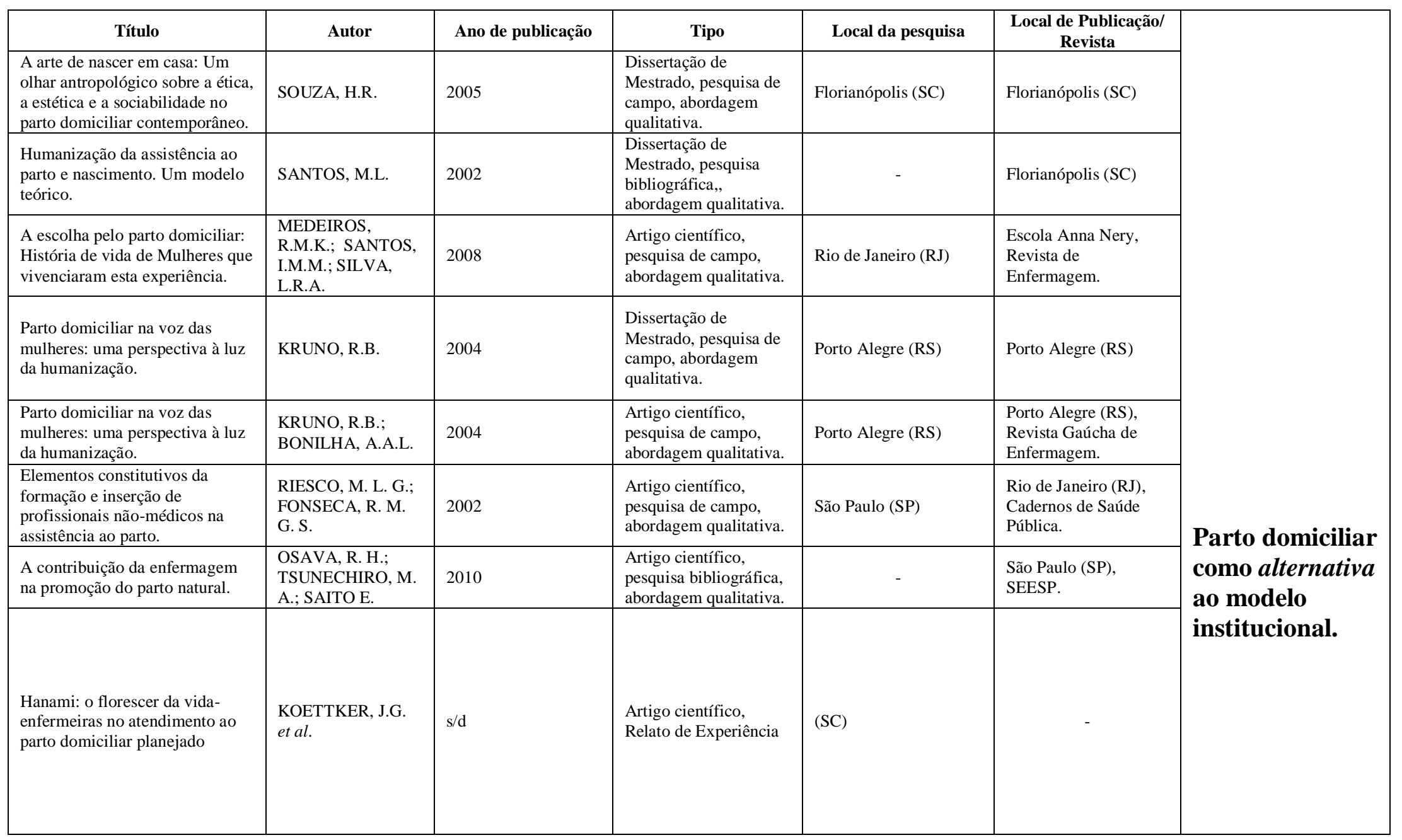


(como defendem alguns autores), existem poucos incentivos à pesquisa sobre esta temática ou 3) que esta modalidade seja considerada ainda irrelevante do ponto de vista de sua expressão enquanto fenômeno social.

Assim, a definição da categoria Parto domiciliar como alternativa ao modelo institucional procurou agrupar as análises que, para além das questões geográficas, localizassem o domicílio como espaço da materialização de uma contra-hegemonia ideológica na forma de conceber o nascimento. Alguns dos estudos selecionados abordam o assunto no corpo do trabalho, mas não como objeto principal, sendo necessário um processo exploratório intenso para a coleta de informações pertinentes.

Deve-se explicitar, contudo, que não se pretende excluir o parto domiciliar assistido por parteiras tradicionais enquanto alternativa ao modelo hospitalar vigente, mas ressaltar a observação de que as condições que permeiam esta modalidade parecem ter maiores influências de processos culturais e da exclusão gerada por uma determinada realidade sócioeconômica, do que a partir de uma motivação de contraposição à estrutura institucional.

É relevante mencionar que se torna difícil traçar um paralelo isolado entre a quantidade e distribuição de estudos de acordo com o local de pesquisa vesus a magnitude do parto domiciliar, visto que existe uma notável desigualdade de incentivos a produções entre as regiões, com maior concentração de publicações no Sudeste e Sul do país. Assim, apesar deste estudo não ter um caráter quantitativo, para início de abordagem considerou-se importante citar algumas informações que auxiliem na compreensão da dimensão da ocorrência dos partos domiciliares no Brasil e subsidiem as analises qualitativas posteriores.

Segundo dados do Instituto Brasileiro de Geografia e Estatística (IBGE, 2009) ${ }^{(51)}$ sobre os registros de nascidos vivos no ano de 2009 - representados no Gráfico 1 aproximadamente $1,25 \%$ dos partos no país ocorreram no domicílio. A região Norte possui um percentual maior que 5 vezes a média nacional, sendo que cerca de $6,5 \%$ dos partos são domiciliares. Neste ranking seguem a região Nordeste $(1,51 \%)$, Centro-Oeste $(0,56 \%)$, Sudeste $(0,27 \%)$ e Sul $(0,21 \%)$, respectivamente. O estado com o maior número absoluto de partos realizados em casa é o Pará, com 7.359 partos em 2009, o que representa 6,23\% dos partos realizados no estado neste mesmo ano.

No Quadro 3, observa-se uma tendência de declínio dos registros de partos de nascidos vivos ocorridos no domicílio a partir de 2003, apesar da natalidade se manter relativamente estável no período. Destaca-se que, se compararmos os registros dos anos de 


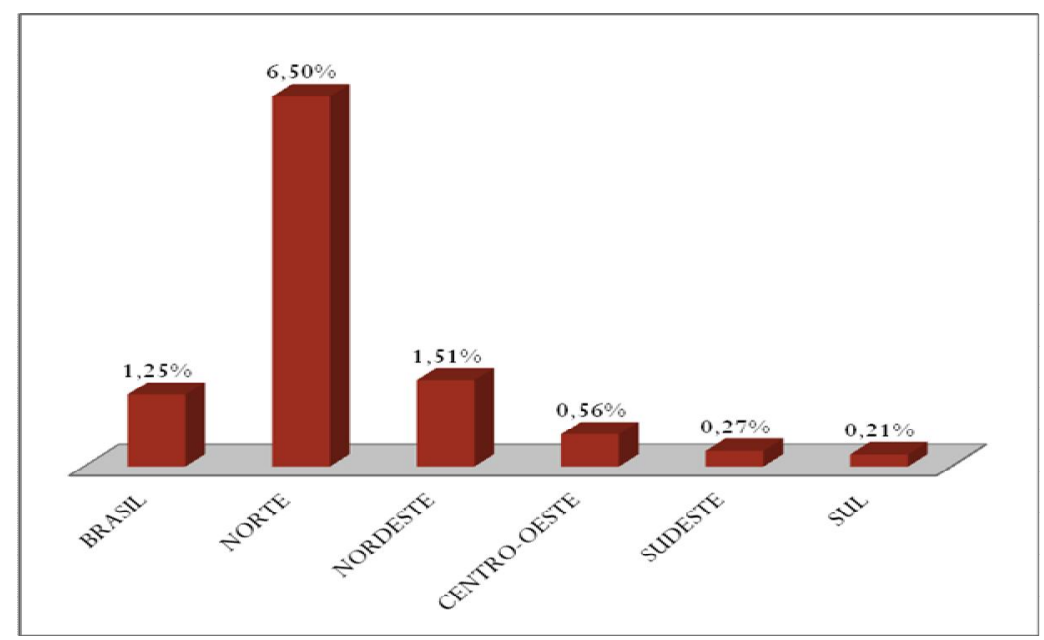

Gráfico 1 - Partos domiciliares por total de nascidos vivos no Brasil e por Região Fonte dos dados: IBGE, 2009.

Quadro 3 - Nascimento por ocorrência por local de ocorrência segundo ano de nascimento.

Período: 1994-2008

\begin{tabular}{|c|c|c|c|c|c|c|}
\hline $\begin{array}{c}\text { Ano no } \\
\text { Nascimento }\end{array}$ & Hospital & $\begin{array}{c}\text { Outro } \\
\text { estabelecimento } \\
\text { de Saúde }\end{array}$ & Domicílio & Outro & Ignorado & Total \\
\hline 1994 & 2.066 .966 & 58.931 & 30.059 & 2.432 & 413.183 & 2.571 .571 \\
\hline 1995 & 2.042 .261 & 54.064 & 27.743 & 1.502 & 699.159 & 2.284 .729 \\
\hline 1996 & 2.234 .968 & 46.240 & 26.862 & 1.201 & 636.144 & 2.945 .425 \\
\hline 1997 & 2.921 .447 & 61.861 & 31.915 & 1.859 & 9.576 & 3.026 .658 \\
\hline 1998 & 3.033 .363 & 71.255 & 35.465 & 2.254 & 5.700 & 3.148 .037 \\
\hline 1999 & 3.149 .412 & 60.319 & 39.638 & 2.915 & 4.149 & 3.256 .433 \\
\hline 2000 & 3.095 .252 & 65.509 & 41.145 & 3.038 & 1.817 & 3.206 .761 \\
\hline 2001 & 3.000 .741 & 61.471 & 48.551 & 3.584 & 1.127 & 3.115 .474 \\
\hline 2002 & 2.957 .873 & 54.147 & 44.378 & 2.388 & 616 & 3.059 .402 \\
\hline 2003 & 2.934 .396 & 55.953 & 45.010 & 2.482 & 410 & 3.038 .251 \\
\hline 2004 & 2.928 .155 & 54.792 & 40.707 & 2.661 & 233 & 3.026 .548 \\
\hline 2005 & 2.945 .989 & 46.391 & 39.410 & 3.058 & 248 & 3.035 .096 \\
\hline 2006 & 2.863 .823 & 41.223 & 37.000 & 2.353 & 529 & 2.944 .928 \\
\hline 2007 & 2.817 .004 & 34.568 & 35.788 & 3.160 & 808 & 2.891 .328 \\
\hline 2008 & 2.865 .801 & 33.572 & 32.744 & 2.460 & 251 & 2.934 .828 \\
\hline
\end{tabular}

Fonte: MS/SVS/DASIS - Sistema de Informação sobre Nascidos vivos - SINASC. 
1994 e 2008, pode-se observar uma drástica queda nos registros de local de ocorrência ignorado que se acentuou em 1997 e apresentou seu menor número em 2008; comparativamente houve um aumento numericamente proporcional nos registros de nascidos vivos em hospitais.

A nível concreto, estes números podem não ser fidedignos, admitindo-se que há subnotificação do parto domiciliar ${ }^{(39)}$ e considerando, ainda, a estimativa de subregistro do total de nascimentos em 8,2\% para o ano de 2009 (IBGE, 2009). ${ }^{(51)}$

No entanto, deve-se destacar que o processo de medicalização e institucionalização do parto foi consolidado e é hegemônico no Brasil, com mais de 98,5\% dos nascimentos em unidades obstétricas (IBGE, 2009). ${ }^{(51)}$ É salutar considerar que, nas ultimas décadas, este processo tem como elemento importante o princípio de universalização do acesso à saúde, preconizado pelo SUS, visto que no modelo biomédico vigente a atenção ao parto relacionase com a prevenção de riscos, a tecnologização das condutas e a hospitalização. Assim, as desigualdades regionais na ocorrência do parto domiciliar nos remetem à existência de uma relação inversamente proporcional aos níveis de cobertura do sistema de saúde. Um exemplo a citar refere-se às consultas pré-natais, que encontram as menores proporções nas regiões Norte e Nordeste. ${ }^{(52)}$

No aspecto socioeconômico pode-se realizar a mesma relação inversamente proporcional, em que se observa que os indicadores negativos de desenvolvimento coincidem com uma maior incidência regional de partos domiciliares. A Pesquisa Nacional de Demografia e Saúde da Criança e da Mulher (PNDS) - 2006 apontou que também nas regiões Norte e Nordeste observam-se os maiores percentuais de nascidos vivos de mulheres analfabetas funcionais, com $18,7 \%$ e $17,1 \%$, respectivamente, números maiores que o dobro do encontrado nas demais regiões do país, que não ultrapassam os $8 \%$. ${ }^{(53)}$

De forma correlata, a maioria dos nascidos vivos residentes na região Norte $(62,5 \%)$ e Nordeste $(68,4 \%)$ enquadrou-se nas classes DE, tendo sido maior a participação da classe C entre aqueles das regiões Sul $(54,2 \%)$, Sudeste $(49,2 \%)$ e Centro-Oeste $(46,5 \%){ }^{(53)}$

Assim, o menor poder aquisitivo da população geral pode ainda explicar a maior presença do SUS na atenção a gestantes e parturientes no Norte e Nordeste, quando existe o acesso aos serviços formais de saúde. ${ }^{(53)}$ Por outro lado, uma maior relevância da participação do sistema suplementar nas regiões Sudeste e Sul, aliado a um maior poder econômico da população em geral, ${ }^{(53)}$ sugere uma maior possibilidade de acesso a serviços que não são 
disponibilizados pelo SUS, como o parto domiciliar realizado por profissionais liberais.

\section{PARTO DOMICILIAR COMO PRÁTICA TRADICIONAL}

A construção da hegemonia do hospital enquanto local de realização dos partos mostrou que é possível subjugar uma tradição secular de parturição quando os interesses para o desenvolvimento de um modelo social estão em jogo. Apesar disto, muitos estudos vêm apontando que existem realidades contemporâneas em que a cultura de parir em casa resiste, não obstante as influências da modernidade e as diferentes condições históricas que permeiam este fenômeno.

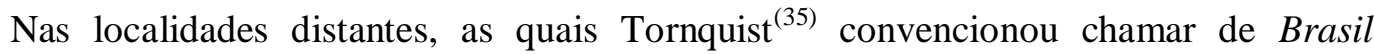
profundo, as mulheres que gestam a vida encontram diversos problemas na busca de 'dar à luz' com segurança e tranquilidade. Nestes locais, onde os serviços de saúde não chegam pelas dificuldades geográficas, pela falta de profissionais ou pela falta de recursos [e de interesse político] para o desenvolvimento local - as parteiras são figuras indispensáveis. ${ }^{(26,54)}$ Detentoras de um saber iminentemente empírico, elas atuam no interstício da modernização e da tecnologização das condutas, marginalmente salvando vidas.

Munidas da fé enquanto instrumento de sua prática, as parteiras deparam-se com o embate cotidiano da falta de assistência à saúde, da necessidade de trabalhar e da sua missão divina. ${ }^{(15,55,56)} \mathrm{A}$ 'arte de partejar' se insere na cultura das comunidades isoladas como uma prática social que ultrapassa os limites ocupacionais e, de maneira geral, se traduz no cotidiano das relações solidárias e afetivas. “[...] sem deixar de desempenhar uma série de outros trabalhos, típicos das classes populares - [as parteiras] não deixam de assistir e/ou atender partos de outras mulheres, com as quais compartilham experiências de vida."(35)

Nesses moldes, o parto domiciliar procede de maneira essencialmente contemplativa e pouco intervencionista, a partir da concepção de que este evento faz parte da natureza humana e que, portanto, a mulher é capaz de enfrentar com êxito. ${ }^{(17,35,57)}$ As mãos são os instrumentos básicos ${ }^{(58)}$ e os artefatos domésticos são os recursos de que se dispõe: tesoura ${ }^{(26)}$ desinfetada no fogo ou álcool; unguentos e óleos para lubrificar o canal de parto ${ }^{(54)}$ e para massagens; chás, macerações, engarrafadas e banhos de assento; ${ }^{(26)}$ simpatias e rezas. ${ }^{(58)}$ A utilização de instrumentos simples, que fazem parte do cotidiano das famílias no espaço doméstico, demonstra que os instrumentos sofisticados que foram introduzidos na obstetrícia com o 
advento da medicalização não são imprescindíveis na prática das parteiras tradicionais. Nesta realidade, portanto, o parto não se configura enquanto um evento a ser controlado, mas assistido.

A autonomia da mulher é um elemento bastante recorrente nas entrelinhas dos trabalhos sobre este assunto. A liberdade de movimentos e posições no trabalho de parto e parto $^{(32,58)}$ e a realização de toques vaginais somente quando há necessidade e permissão da parturiente $^{(58)}$ sinalizam que a mulher é considerada sujeito ativo e protagonista do parto. Portanto, observa-se que a cultura tradicional da parturição apresenta consonâncias práticas com os princípios da humanização do parto, em contraposição à realidade desoladora de violência institucional e de condutas desumanizadas descrita por diversos autores acerca das maternidades e centros obstétricos brasileiros.

Ressalta-se que, sendo o Brasil um país com proporções continentais, deve-se considerar que a grande diversidade cultural imprime distinções nos procedimentos, nas condutas e no arsenal do parto nas diferentes comunidades. A cauterização do cordão umbilical, por exemplo, é uma prática muito comum entre as parteiras do Jequitinhonha utilizada eficazmente no processo de cicatrização do coto, apesar de não recomendada pelos profissionais de saúde devido ao risco de acidentes. ${ }^{(58)}$ No entanto, não observamos relatos do uso deste procedimento em outros estudos sobre o tema, o que pode indicar que seja adotado especificamente pelas parteiras desta região.

Em contraponto à tradição homogeneamente feminina das parteiras populares, encontramos menção a parteiros (homens) no trabalho de Pinto, ${ }^{(55)}$ realizado na região do Tocantins, estado do Pará. Na divisão do trabalho, os parteiros homens ficam a cargo rezar, fazer simpatias e ordenar o que deve ser feito pelas parteiras auxiliares (mulheres). Nesta situação, verifica-se uma clara expressão da divisão sexual do trabalho a partir das relações de gênero. Com as devidas proporções, é possível comparar este fenômeno com o processo histórico de dominação masculina na 'arte de curar' e, mais especificamente, na 'arte de partejar', através das concepções acerca de uma suposta superioridade técnica e intelectual do homem.

O pré-natal informal também apresenta diferenças de acordo com a localidade. $\mathrm{Na}$ Vila da Barra do Superagui o acompanhamento inicia-se durante a gestação e no Jequitinhonha é comum o contato com a parteira só no trabalho de parto. ${ }^{(58)}$ No Melgaço (PA) a puxação, uma massagem abdominal, é a principal prática pré-natal e, além do uso de chás, 
banhos e rezas, são coletadas importantes informações sobre as condições de saúde da mãe do bebê, a história dos partos da família, a ocorrência de distócias, a estrutura familiar, as condições do domicílio e a existência ou não de recursos para o caso de uma emergência. ${ }^{(59)}$ Atenta-se que não se pode generalizar afirmando que os partos domiciliares realizados por parteiras populares não sejam planejados, ainda que esta seja a única opção existente para muitas famílias.

Além das diferenças culturais, podemos observar, através do trabalho de Aires, ${ }^{(58)}$ diferentes condutas no parto entre gerações de parteiras de uma mesma comunidade. De acordo com a autora, as parteiras mais jovens da região do Vale do Ribeira (PR), por exemplo, sob a alegação de que a maioria das casas não apresenta assoalho adequado, vêm deixando de usar uma caixinha de madeira que auxilia a mulher a se manter numa posição verticalizada no período expulsivo, um instrumento muito comum entre as parteiras contemporâneas mais idosas. Em consonância com Aires, ${ }^{(58)}$ considera-se que, entre as mais jovens, há uma maior preocupação com relação à higiene do local do parto e quanto ao próprio conforto. Percebe-se que o discurso higienista propagado pela medicina social nos séculos XIX e XX para deslegitimar a atuação das 'parteiras leigas' e para justificar a institucionalização do parto foi incorporado ao senso comum nos dias atuais. Isto corrobora com a forte influência do modelo hospitalar de atenção e a eficácia do projeto de medicalização da sociedade. Além disso, a valorização conforto da parteira em detrimento da parturiente nos remete a influências do modelo biomédico que historicamente posicionou o obstetra no protagonismo da assistência ao parto, sendo que a transformação da posição ginecológica em rotina é uma expressão prática da generalização de uma conduta em prol da comodidade do médico, desvelando a retirada da centralidade da mulher e do bebê na assistência.

Em seu estudo qualitativo com parteiras dos estados de Minas Gerais e Rio de Janeiro, Batista $^{(56)}$ inferiu acerca da forte relação de poder exercida pela figura médica sobre a parteira, resultando na adesão de conhecimentos científicos à sua prática de forma não reflexiva. É importante pontuar que, em especial a partir do incentivo do Ministério da Saúde à realização de cursos de capacitação, o saber e a prática das parteiras tradicionais vêm sofrendo grande influência da biomedicina. Sobre esta questão, Fleischer ${ }^{(60)}$ observou que, com os cursos, as parteiras começaram a agregar uma linguagem biomédica e Barroso ${ }^{(26)}$ refere que parteiras que recebem treinamento acolhem bem as novas técnicas e conhecimentos e que o 
oferecimento de kits de parto tende a alterar o estilo da tradição do partejar. No entanto, Aires ${ }^{(58)}$ observou que, quando as parteiras consideram ineficaz o que foi aprendido nas capacitações, voltam a fazer "do seu jeitinho".

Em diversos estudos ${ }^{(15,17,26,35,55,56,57,61)}$ é possível identificar que a solidariedade, a fé e o trabalho de partejar enquanto dom divino se entrelaçam e são atribuídos como características quase inatas das parteiras. Assim, o tratamento dispensado e o pagamento pelo trabalho geralmente procedem de acordo com a situação financeira da família, ${ }^{(55)}$ sendo comum o pagamento em espécie (galinhas, frutas etc.), em consonância com a lógica da dádiva. ${ }^{(35)}$ Há ainda algumas parteiras que reivindicam o pagamento do SUS pela assistência ao parto, como ocorre em algumas cidades, onde as prefeituras que aderem repassam $\mathrm{R} \$ 13,75$ de recursos do PAB por parto realizado. ${ }^{(15)}$ Todavia, em Barroso $^{(26)}$ verifica-se que a recompensa pelo trabalho desempenhado ultrapassa os valores monetários e assume valores subjetivos, como o reconhecimento na comunidade, o amadrinhamento e a satisfação de ver as crianças e mulheres sadias.

No entanto, as parteiras do estudo de Fleischer ${ }^{(60)}$ distavam "da imagem frágil e incauta que a literatura vem teimando em lhes atribuir". A autora comenta que as parteiras mais jovens começam a desassociar a questão de partejar com o dom e que, quando havia uma relação com as religiões evangélicas ocorria uma maior naturalização em lidar com o dinheiro. A partir deste trabalho, observou-se a inserção da lógica do capital e um crescente processo de profissionalização das parteiras, em que as mulheres passam a ser clientes, diante

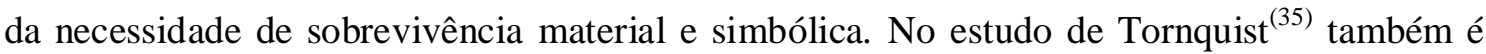
possível notar a existência de uma discrepância com o que vêm se pautando na literatura nos últimos anos:

Fica clara a preocupação da parteira em "deixar" testemunho diante de possíveis acusações, assinalando que, nessas regiões, coexistem, de forma tensa e ambígua, atitudes de confiança e de legitimidade e atitudes de desconfiança e temor frente às parteiras e suas formas de assistência. ${ }^{(35)}$

Diante disto, pode-se sugerir a existência de movimentos contrários: ao passo em que a confiabilidade é deslocada enquanto atributo do ser parteira para uma característica com valor individual, a desconfiança é considerada diante do processo histórico de deslegitimação da prática parteiras pela biomedicina e pelo senso comum. 
Em muitos locais, entretanto, se ocorre alguma anormalidade a experiência e a perícia da parteira são os únicos instrumentos aos quais se pode recorrer. Fleischer ${ }^{(59)}$ alude que se torna essencial a identificação prévia sobre se o parto é 'para casa' ou 'para o hospital'. Dessa decisão pode depender a vida da mulher e do bebê. Quando há a necessidade de encaminhar a parturiente ao hospital o caminho a se percorrer pode ser bastante difícil, dando início a uma longa peregrinação. "Partos difíceis, ou mesmo aqueles que tudo teriam para serem normais e que se agravam [...] pedem mais do que solidariedade".(15)

Em diversas cidades brasileiras, há deficiência ou mesmo inexistem leitos obstétricos. Em localidades como Melgaço, no Arquipélago do Marajó (PA), e no Arquipélago do Bailique, pertencente ao município de Macapá (AP), 100\% dos partos são domiciliares, assistidos por parteiras tradicionais. ${ }^{(39)}$ Como admite o Ministério da Saúde, ${ }^{(39)}$ esses partos ocorrem “de forma precária e em situação de exclusão e isolamento", desassistidos pelo SUS.

As regiões Norte e Nordeste do Brasil se destacam no cenário de abandono do poder público, apresentando os mais altos índices de partos assistidos por parteiras tradicionais, com $5,8 \%$ e $3,6 \%$ dos nascidos vivos, respectivamente. ${ }^{(62)}$ Isto contrasta com a realidade nas regiões Sul, Sudeste e Centro-Oeste, onde se concentra maior número de instituições hospitalares e maternidade ${ }^{(56)} \mathrm{e}$, portanto, há uma menor atuação das parteiras populares, levando a "deduzir que os espaços não ocupados pelos médicos [...] são os espaços onde a maioria das parteiras ainda continua desempenhando a arte de partejar". ${ }^{(56)}$ Acresce-se que a maioria das autoridades sanitárias e profissionais de saúde não reconhecem a atuação das parteiras, ${ }^{(55,59)}$ nem a necessidade de incorporar o parto domiciliar à atenção básica, como responsabilidade do SUS - considerando ainda que a Estratégia de Saúde da Família (ESF) assiste a menos de $51 \%$ da população brasileira (BRASIL, 2010). Como consequência direta desta situação, tem-se um alto índice de subnotificação de partos domiciliares no país, ${ }^{(39,58)}$ sugerindo, ainda, uma considerável subnotificação de mortes materna e neonatal.

O que assistimos no interior, principalmente nas regiões Norte, Nordeste e Amazônica são partos realizados nas residências pobres, insalubres e miseráveis de milhares de mulheres que moram em áreas longínquas, sendo atendidas por mulheres fortes, de boa vontade, mas muitas vezes despreparadas ou sem recursos para tal função. ${ }^{(15)}$

Nascimento et $\mathrm{al}^{(15)}$ nos incita a refletir sobre a qualidade da atenção dispensada às mulheres pelas parteiras. Ao contrário da romantização promovida por diversos autores, 
atenta-se para as possíveis carências materiais e humanas da assistência ao nascimento nas comunidades isoladas. Não se pretende desqualificar o saber cultural da parturição, mas incluir nesta análise o caráter histórico, político e social que localiza esta prática sem, contudo, deixar de reconhecer as habilidades que a experiência e a tradição oral conferem. Pode-se aludir que, atualmente, o trabalho das parteiras revela o abandono do sistema de saúde. ${ }^{(15)} \mathrm{E}$, além disso, é um indicativo do desamparo do poder público a comunidades que permanecem em situação de exclusão e extrema pobreza, configurando um problema que ultrapassa a atenção ao parto e se expressa no cotidiano de milhares de brasileiros que enfrentam o desemprego, a fome e a sede, as precárias condições sanitárias, o transporte deficiente e a falta de acesso a serviços de saúde, educação e lazer. Percebe-se o grande desafio de consolidar e ampliar o SUS sob os pilares de uma sociedade baseada numa velha estrutura capitalista que, em essência, pressupõe a existência de desigualdades e exclusão social.

Contudo, apesar das dificuldades enfrentadas, muitas mulheres escolhem realizar o parto domiciliar assistido por parteiras tradicionais, principalmente devido ao atendimento desumanizado e medicalizado dos hospitais, bem como as dificuldades de acesso aos serviços de saúde. ${ }^{(35,58,60)}$ A noção de escolha se relativiza neste contexto, pois, apesar da carência de oportunidades de realizar o parto em outras condições, para muitas mulheres o parto domiciliar realizado por parteiras tradicionais se torna preferível ao parto institucional, significando também, a possibilidade de desfrutar de uma maior segurança física e emocional.

\begin{abstract}
Verdadeiros périplos em busca de transporte, peregrinações atrás de uma maternidade disposta a atender o parto, médicos não localizados na hora de seus plantões, maus-tratos e violência dos profissionais de saúde para com parturientes e parteiras compõem um repertório dramático de histórias de parto locais, que convidam a relativizar noções modernas de perigo, de risco e de dificuldade em geral associadas aos partos em domicílio [...]. ${ }^{(35)}$
\end{abstract}

Outros elementos foram identificados como vantagens do parto domiciliar em alguns estudos: menor intervenção, a possibilidade do apoio familiar, liberdade de posições e de comportamento, possibilidade ficar com os filhos mais velhos e menor gasto financeiro. ${ }^{(32,58)}$

É importante destacar a iminência de perda dos valiosos conhecimentos da tradição popular da parturição, devido à considerável redução do número de parteiras tradicionais nas ultimas décadas, ${ }^{(56)}$ bem como à dificuldade em dar continuidade à transmissão oral deste saber. ${ }^{(55)}$ 


\section{PARTO DOMICILIAR COMO ALTERNATIVA AO MODELO INSTITUCIONAL}

Ao refletir sobre a emergência do parto domiciliar enquanto uma prática contrahegemônica, remete-se à existência basal de uma oposição à condição e à concepção dominante que, em primeira instância, desvela um conflito de interesses. A História nos mostra que a construção da hegemonia do modelo biomédico no âmbito da assistência ao parto e nascimento significou, em suas entrelinhas, o controle das forças produtivas e, portanto, um controle coletivo em prol de interesses de mercado das classes mais abastadas. No entanto, a construção desta hegemonia necessariamente perpassa a construção de práticas cotidianas que garantam o controle sobre indivíduos.

Neste contexto, a instituição é o espaço que favorece a apropriação dos corpos, tendo como estratégias de dominação in locus as relações hierárquicas de poder, a normatização, a tecnologização das condutas e a patologização. Como refere Kruno, ${ }^{(33)}$ há uma omissão da fisiologia do parto, ao passo em que os partos sempre são considerados de risco, como forma de justificar o intervencionismo e a suposta necessidade de monitoração deste evento. $\mathrm{O}$ mesmo autor menciona a existência de um processo de condicionamento do sistema, que formata os profissionais a uma prática preocupada com o número de atendimentos em detrimento da qualidade do serviço.

Sob uma perspectiva mais ampla, a instituição/hospital/maternidade é a célula em que os valores e concepções sobre o modo de viver e o modo de nascer se materializam.

Durante o período em que permanece sob a tutela da instituição, a mulher é destituída de direitos, sendo-lhe retirada a autonomia, a privacidade, o direito de ir e vir e o direto sobre o próprio corpo, relegada a uma posição de paciente. O que é normal acaba por se diferenciar do que é natural e fisiológico, e os recursos que deveriam ser usados somente quando necessário são transformados em rotina. A subjetividade é desconsiderada dando lugar ao tecnicismo (muitas vezes iatrogênico), e o parto se transfigura em momentos de privação relacional, comportamental e afetiva.

[...] o 'excesso de tecnologias', de pessoas envolvidas 'tecnicamente' e não "afetivamente" no parto, além do ambiente 'estranho' e não 'familiar' à parturiente e sua família, não permitem que a beleza do parto se manifeste, tornam-no estéril, socialmente improdutivo. ${ }^{(6)}$ 
Percebe-se que o hospital não é apenas o cenário do parto, pois influencia e legitima as relações que se procedem. Na esfera das microrrelações, podemos observar que o hospital, enquanto território estranho, alheio e não-familiar, condiciona o não-empoderamento da mulher e a coloca em uma posição de heteronomia.

Contrariamente, a casa se configura em um ambiente próximo, familiar e, a priore, seguro do ponto de vista físico e emocional, onde a liberdade e a autonomia dos envolvidos oferecem maiores condições de manifestação do protagonismo tão enfatizado na Política Nacional de Humanização. É um "ambiente facilitador do parto natural”, (13) na medida em que, ao proporcionar uma maior sensação de privacidade e conforto, "contribui para o equilíbrio hormonal, o elemento mais importante e influente no resultado do parto".. (38) "[...] o que proporciona a sensação de segurança é o que está ao "alcance da mão", que é "conhecido" e tem a solidez daquilo que pode ser manejado. ${ }^{(6)}$

Compreende-se que o parto, concebido enquanto parte da natureza e da história de vida humana, assume o status de fisiológico e, ao mesmo tempo, de cultural.

Delineando o distanciamento da concepção de que a gestação, o parto e o nascimento são potencialmente patológicos, ser saudável e ativa torna-se condição essencial nesta modalidade (SOUZA, 2005), quando se considera que uma gestação saudável está relacionada a uma vida saudável, e que o natural se harmoniza com o fisiológico.

[...] os hábitos cotidianos da mulher têm tanta influência quanto à sua atitude mental em relação a dar à luz. Mulheres que se exercitam regularmente estão mais bem preparadas para o trabalho de parto do que aquelas que levam uma vida sedentária. ${ }^{(38)}$

Ademais, o domicílio vem a proporcionar o intimismo no resgate do parto e nascimento enquanto "rito de passagem". ${ }^{33)}$ O preparo do corpo físico e mental e do ambiente ${ }^{(33,63)}$ a valorização da subjetividade e do vínculo entre os participantes ${ }^{(6)}$ - cada detalhe é importante e imprime o caráter único e pessoal que envolve este momento na vida dos indivíduos. Neste sentido, é imprescindível a construção de uma relação de confiança e o envolvimento emocional e afetivo e entre todos os participantes deste processo, ${ }^{(6)}$ inclusive com o profissional que assiste ao parto. ${ }^{(63)}$ Ressalta-se que todos os sujeitos envolvidos têm possibilidade de desempenhar uma participação ativa no parto domiciliar, ainda que se enfatize o protagonismo da mulher e do bebê. ${ }^{(6)}$ 
Nota-se que o pré-natal, neste contexto, ganha uma dimensão ampliada, em que a de prevenção de riscos, enfatizada na concepção biomédica, é apenas mais um elemento de uma preparação para o parto que ultrapassa as noções biológicas e se configura no cuidado do corpo, da mente, da espiritualidade, do ambiente, do contexto e das relações interpessoais. Portanto, "o atendimento médico faz parte do pré-natal, ele não é o pré-natal". (6)

Neste viés, a busca de informações e a construção de conhecimentos junto ao profissional que assistirá ao parto são consideradas dos preparos mais importantes, ${ }^{(63)}$ possibilitando à mulher assumir sua autonomia e promover o autocuidado. ${ }^{(6)}$ Assim, torna-se conveniente a escolha de profissionais que se adéquem às convicções e concepções da mulher. ${ }^{(33)}$

Segundo pesquisa de Medeiros, Santos e Silva, ${ }^{(13)}$ o acesso a informações parece ser um importante elemento de influência no processo decisório pelo parto domiciliar, e foi facilitado por um maior nível de escolaridade e socioeconômico. Souza ${ }^{(6)}$ infere sobre a importância da internet enquanto instrumento de difusão de informações. Atualmente existem diversos sites que divulgam os benefícios do parto normal e natural; o uso de técnicas e terapias alternativas para o pré-natal, parto e pós-parto e que oferecem serviços de parto domiciliar. No entanto,

Infelizmente a maioria da população de gestantes no Brasil não possui acesso a estes conhecimentos, seja por possuírem uma condição socioeconômica inferior e baixo nível de escolaridade que impedem o acesso, seja pela negligência dos profissionais de saúde que não consideram a escolha informada um direito da mulher. ${ }^{(13)}$

Há, ainda, um forte apelo da mídia que reforça a concepção patológica do parto. Contrariamente, a mídia seria um importante instrumento para desmistificar o parto ${ }^{(63)} \mathrm{e}$ divulgar os benefícios e vantagens do parto natural e em casa, devido ao amplo acesso da grande maioria da população, em especial, à rede televisiva.

Encontramos, nas pesquisas, diversas vantagens e benefícios do parto domiciliar, que acabam por se confundir com as motivações das mulheres na escolha por esta modalidade. Liberdade para escolha, ${ }^{(13)}$ para alimentar-se e para movimentar-se; ${ }^{(6)}$ liberdade de posições, de comportamentos e expressões ${ }^{(33)}$ - pode-se afirmar que a liberdade, como exercício da autonomia e autodeterminação, aparece como elemento chave no parto domiciliar. Neste sentido, a familiaridade, a informalidade, a simplicidade e a presença de familiares e amigos escolhidos para vivenciar este momento, ${ }^{(63)}$ são elementos que contribuem para o 
estabelecimento de uma liberdade para socializar com privacidade e conforto, o que, em geral, não é permitido nas maternidades.

Devido à ausência de normas e rotinas, no parto domiciliar há também a possibilidade de uma interação imediata entre a mulher e o bebê e uma maior disposição física e mental da mulher. ${ }^{(33,63)}$

A medicalização do parto, nas instituições hospitalares resulta frequentemente, em mulheres no pós-parto (ou pós-cesáreas), exaustas, sonolentas, queixosas de dor, imóveis, o que vem a dificultar a interação da mãe com seu bebê, no período imediato ao nascimento. ${ }^{(33)}$

Observou-se, contudo, que o parto domiciliar não exclui a monitoração contínua da mãe e do bebê pelo obstetra (tensão arterial, contrações, batimentos cardiofetais, condições gerais etc) ${ }^{(33)}$ bem como o uso de instrumentos e procedimentos como a sutura, por exemplo, se necessário. ${ }^{(6,64)}$

Nesses moldes, o modelo holístico parece aproximar-se das características demandadas pelos adeptos do parto domiciliar, a partir da conjugação de elementos de diferentes paradigmas e filosofias utilizados a serviço do indivíduo e da família.

A partir do ponto de vista das mulheres que adotam o estilo de pensamento holístico de nascimento, a família é considerada uma unidade social significativa. Dentro deste paradigma os rituais de nascimento devem reforçar e reafirmar a unidade da família e dos indivíduos que a compõem, ao invés de reforçar mensagens sobre a primazia da ciência, tecnologia e instituições. Todos estes fatores têm seu lugar, mas este lugar deve necessariamente servir, ao invés de explorar, à natureza, aos indivíduos, famílias e mais especificamente às parturientes [...] No modelo holístico a ciência e a tecnologia são colocadas a serviço do indivíduo. ${ }^{(65)}$

Kruno $^{(33)}$ refere que, no modelo holístico, o parto é visto enquanto um processo natural, a mulher é protagonista e participa do processo decisório junto à equipe que a assiste.

Além das vantagens imediatas já observadas, cogita-se a existência de benefícios em longo prazo, como repercussões no comportamento e na personalidade dos filhos do parto domiciliar, que "são caracterizados como crianças calmas e inteligentes devido à forma como foram recebidos em seus nascimentos". ${ }^{(63)}$

Apesar de todas as proficuidades, o parto domiciliar na atual conformação social vai de encontro a um forte arcabouço ideológico dominante que fundamenta a suposta necessidade de institucionalizar e medicalizar o parto, permeando o senso comum. As mulheres que optam por dar à luz em suas casas assumem um enfrentamento que perpassa deste o modelo hegemônico à própria família e entes próximos, ${ }^{(13)}$ com reações comuns de 
surpresa e negativismo, a partir da projeção de imagens estereotipadas sobre o parto. ${ }^{(6,33,63)}$ Parece-nos que a "convicção interna" de que Kruno ${ }^{(33)}$ fala, enquanto característica marcante comum a estas mulheres, juntamente com as maiores possibilidades de acesso a informações e serviços, influi potencialmente na escolha pelo parto domiciliar, diante da insatisfação com o tipo de assistência prestada nas maternidades e centros obstétricos brasileiros.

O descontentamento com este tipo de assistência e a sensação de que perderiam muitas coisas ao se entregarem sem questionamentos às rotinas rígidas da obstetrícia tradicional impulsionaram estas mulheres a buscarem um modelo de assistência que respeitasse o processo de gestar e parir e lhes pudesse proporcionar um nascimento que ocorresse de forma fisiológica e natural. ${ }^{(13)}$

Em suma, a defesa do parto domiciliar emerge no bojo de uma oposição casa $x$ hospital $^{(6)}$ que excede as noções espaciais, e se configura enquanto uma "saída para reverter o atual modelo assistencial", ${ }^{66)}$ representando mais uma opção para gestantes de baixo risco na tentativa de realizar um parto mais natural e independente da burocracia, normas e rotinas das instituições hospitalares. ${ }^{(6,13,63)}$ Coloca-se como uma possibilidade de devolver aos sujeitos a vivência de aspectos objetivos e subjetivos envolvidos neste processo de forma mais intensa, pessoal, autônoma e humana.

Desta forma, alguns setores consonantes com práticas mais humanizadas defendem a possibilidade da realização de partos em casa com segurança e conforto.

Há, contudo, muitos impasses acerca das competências e qualificações necessárias para prestar assistência ao parto natural, em meio ao questionamento do parto enquanto ato médico e diante da "[...] diversidade de agentes que prestam essa assistência - obstetrizes, enfermeiras, auxiliares, parteiras tradicionais, agentes de saúde etc. [...]."(66)

Torna-se bastante difícil traçar um perfil fidedigno dos profissionais que assistem ao parto domiciliar nas zonas urbanas, pois não foram encontradas fontes que subsidiassem este tipo de análise. Sugere-se, no entanto, uma relevância da participação das enfermeiras, devido ao fato de que todos estes trabalhos foram realizados por pesquisadores desta categoria profissional. Pode-se sugerir que a prática da enfermeira apresentaria consonância com a demanda de uma assistência menos intervencionista e mais humanizada no parto domiciliar, o que Koettker et al ${ }^{(64)}$ refere como "papel de facilitadora" deste processo. Isto justificaria o incentivo do Ministério da Saúde à formação de Enfermeiras Obstétricas a partir do ano de 1999. "Grande parte das enfermeiras obstétricas que atuam nas grandes cidades vê o parto 
como um evento natural, que, se estiver bem acompanhado no pré-natal e livre de complicações, pode ocorrer fora do ambiente hospitalar."(13)

Não podemos afirmar, todavia, em que medida esta prática resultaria de uma formação centrada no cuidado e no respeito à fisiologia do parto ou das restrições à prescrição e execução de certos procedimentos e condutas de forma autônoma por serem considerados atos médicos.

Kruno $^{(33)}$ menciona a assistência médica a partos domiciliares, mas chamou-nos a atenção que, no trabalho de Koettker et $\mathrm{al}^{(64)}{ }^{(64)}$ o médico encontra-se na "retaguarda" da assistência, requisitado apenas quando é necessária alguma intervenção.

De qualquer modo, Santos ${ }^{(65)}$ refere que as pessoas que assistem ao parto domiciliar atuam em uma situação "marginal, se não antagônica, ao modelo vigente".

Fato é que o parto domiciliar nos grandes e médios centros vem se configurando enquanto uma possibilidade atuação no mercado privado da saúde, em especial para a enfermeira obstétrica, ${ }^{13,64)}$ direcionado à um público que pode pagar para vivenciar um parto seguro no conforto de suas próprias casas.

Deve-se citar, todavia, que o trabalho de Souza ${ }^{(6)}$ apontou para a existência de outros sujeitos na assistência ao parto na cidade de Florianópolis que, apesar de, em geral, possuírem formação universitária, não necessariamente são profissionais de saúde. Ela intitula como parteiras(os) urbanas(os) as mulheres e homens que se munem de conhecimentos de maneira autodidata [ou informal] e conjugam diversos saberes e filosofias, com influências de uma cultura neoespiritualistas. Compreendemos que a legitimidade da atuação destes parteiros estaria fundamentada na premissa de que o parto e o nascimento são eventos naturais e fisiológicos e que, portanto, não haveria necessidade de uma formação científica especializada para a sua atuação. Isto faz emergir questionamentos acerca da necessidade ou não de haver uma formação acadêmica superior para habilitar um indivíduo a prestar assistência ao parto natural e, portanto, sobre a reavaliação da gestação enquanto condição de risco.

Souza ainda contextualiza a emergência do parto domiciliar ante a existência de um processo de valorização contemporânea da simplicidade e do intimismo na esfera do parto que, para além de um resgate do passado, remete ao ensejo da construção de uma nova sociabilidade sob uma perspectiva diferenciada de partejar e de viver. Observa-se, portanto, que a modalidade colocada em questão não diz respeito à prática cultural das parteiras tradicionais, mas se coloca a partir de uma demanda de determinados estratos das camadas 
médias de centros urbanos acerca de uma nova "arte de viver dentro da qual a arte de nascer toma seu lugar". ${ }^{(6)}$ Da mesma maneira, Osava, Tsunechiro e Saito, ${ }^{(67)}$ Kruno e Bonilha ${ }^{(63)}$ e Kruno $^{(33)}$ observam que os adeptos do parto domiciliar urbano fazem parte de um público bastante seleto, mas crescente, de mulheres das classes mais favorecidas, o que coincide com as maiores possibilidades de acesso a serviços particulares que não são disponibilizados pelo SUS, como o parto domiciliar, favorecido pelo maior poder econômico e por maior acesso a informações.

Ressalta-se que o parto domiciliar não é indicado quando a residência não oferece condições essenciais à assistência, sendo, nesses casos, "mais seguro e indicado o ambiente institucional". ${ }^{68)}$ Sob este ponto de vista nos parece contraditório que o parto domiciliar tenha inserção nas medidas governamentais somente na esfera da atuação de parteiras tradicionais, pois essas práticas culturais geralmente coincidem com realidades de pobreza e exclusão social que sugerem a precariedade das condições de vida e, consequentemente, de habitação. A tentativa de humanizar a assistência ao parto nesses locais, onde geralmente há uma cobertura insatisfatória dos serviços de saúde, a partir do treinamento de parteiras tradicionais, nos remete à relativização das noções de segurança e humanização se compararmos com a realidade que cerca a defesa do parto domiciliar nas zonas urbanas.

Esta condição perpassa, ainda, a representação social do profissional que assiste ao parto, prevalecendo "a defesa de médicos e parteiras mais qualificadas para mulheres urbanas, ricas"(66) $^{(6)}$ parteiras tradicionais para as classes menos favorecidas.

Em termos práticos, os argumentos e valores que justificam o domicilio como ambiente para os partos de mulheres com gestação considerada de baixo risco são diferentes a depender da situação socioeconômica em que as mulheres se encontram.

\section{ALGUMAS CONSIDERAÇÕES}

Diante dos resultados desta pesquisa, foi possível constatar que, atualmente, convivem de forma antagônica realidades bem distintas que caracterizam o parto domiciliar no Brasil. Uma dessas realidades é condicionada pela ineficiência do poder público em assistir integralmente a saúde das camadas menos favorecidas da população, em especial nas zonas rurais. A outra reflete a busca de uma assistência ao parto alternativa ao modelo institucional, devido ao descontentamento de uma (ainda) pequena parcela das classes médias esclarecidas 
e de nichos do setor saúde que defendem a revisão do modelo atual de atenção ao parto e a construção de concepções mais humanísticas e integrais. Nestes diferentes contextos, são distintos também os agentes da assistência, sendo que os profissionais mais qualificados do ponto de vista de sua formação científica formal prevalecem para as classes mais abastadas e as parteiras tradicionais ficam a cargo de assistir as mulheres das camadas mais pobres. Há, ainda, uma significante desigualdade regional na ocorrência do parto domiciliar, em que a sua maior incidência coincide com os menores níveis de cobertura do sistema de saúde e com os mais baixos indicadores de desenvolvimento. Notou-se que, diante de uma realidade desoladora de violência institucional e práticas e condutas desumanizadas nas maternidades e centros obstétricos brasileiros, o parto domiciliar se justifica enquanto ambiente para os partos de mulheres com gestação considerada de baixo risco, mas os argumentos e valores que o colocam como alternativa são diferentes a depender da situação socioeconômica em que se encontram.

O Ministério da Saúde, desde 2000, vem construindo um discurso de defesa da humanização e da desmedicalização do parto e nascimento, em consonância com as tendências dos principais órgãos internacionais de referencia na Saúde. No entanto, suas medidas não têm representado avanços significativos no processo de desmedicalização, mesmo diante de propostas mais consonantes com a institucionalização, como a Criação de Centros de Parto Normal, num contexto de grande pressão da comunidade médica pela manutenção do atual modelo hospitalocêntrico-medicalizado. A Política Nacional de Humanização, apesar de representar grande esperança na consolidação dos princípios do SUS, no âmbito do parto e nascimento, se implementada de maneira isolada, sem articular um processo de desospitalização, vem a resignificar a intencionalidade de 'reformar' e 'melhorar' a estrutura vigente, sem modificar radicalmente os valores, concepções e práticas que envolvem este evento. Acerca do parto domiciliar, o Programa Trabalhando com Parteiras Tradicionais remete ao reconhecimento de deficiências na assistência ao parto de comunidades isoladas, todavia, percebe-se que esta medida não sana esta problemática do acesso aos serviços de saúde, dando continuidade a uma lógica de diminuição de custos, sob um discurso de valorização das parteiras tradicionais.

Percebe-se que, em termos práticos, há uma desvalorização do saber tradicional das parteiras e da importância de sua atuação, mesmo ante as carências dos serviços de saúde e a comprovação científica de que muitas de suas condutas são benéficas e humanizadas. Torna- 
se cogente valorizar, investigar e registrar os elementos desta prática cultural no Brasil, através de pesquisas mais específicas quanto ao objeto e amplas do ponto de vista geográfico, tendo em vista a grande diversidade cultural que imprime diferenças nas condutas e procedimentos, bem como a dificuldade em dar continuidade à transmissão oral deste saber, para que os conhecimentos seculares, construídos ao longo das gerações, não se percam e possam ser aplicados.

É relevante explicitar que as condições socioeconômicas das comunidades em que comumente as parteiras atuam, podem influenciar e motivar os comportamentos solidários, gerando uma recorrência na manifestação desta característica. Entretanto, deve-se ponderar que os sujeitos possuem uma individualidade e histórias de vida que lhe são particulares, conferindo competências, valores e características individuais. Portanto, ao se analisar qualquer categoria ou grupo, as tendências devem ser consideradas, mas não transformadas em padrões, para evitar romantizações. Não se deve, também, observar os fenômenos de forma anacrônica e imutável. Assim, considera-se a existência do caráter histórico, que torna a realidade passível de um processo contínuo de mudanças da conjuntura, das concepções ideológicas, do espaço e da estrutura social, das coletividades, das representações sociais, das práticas e dos indivíduos, em uma constante retroalimentação.

Este estudo não pretendeu definir diretrizes acerca das competências e qualificações necessárias para prestar assistência ao parto, sendo mister a realização de pesquisas e elaborações teóricas específicas para este fim. Porém, num contexto em que a assistência ao parto é considerada ato médico, é proeminente a existência de diversos sujeitos não médicos e, inclusive, alguns não habilitados a prestar assistência à saúde, o que nos faz inquirir sobre a necessidade ou não de haver uma formação acadêmica superior para habilitar um indivíduo a prestar assistência ao parto natural. Apesar destas indefinições, é imprescindível a reformulação do ensino obstétrico, de maneira a agregar à formação uma lógica menos intervencionista e mais humanística, bem como assumir de maneira prática o conceito amplo de pré-natal enquanto uma preparação biopsicossocial da mulher e da família para o parto, nascimento e maternagem.

Compreendendo que a melhoria das condições de nascimento depende da melhoria das condições de vida da população, apresenta-se a necessidade de investir no desenvolvimento humano em seus diversos aspectos, como saúde, alimentação, educação, trabalho, transporte, lazer, habitação. É um grande desafio efetivar os princípios de universalidade, equidade e 
integralidade do SUS, bem como ampliar as ações de promoção da saúde, quando se tem um modelo de atenção que valoriza predominantemente as ações curativas e preventivas.

Esta pesquisa ainda possibilitou concluir que, mais do que uma opção para gestantes de baixo risco que buscam realizar um parto mais natural e independente da burocracia, normas e rotinas das instituições hospitalares, o domicílio foi identificado enquanto um espaço que favorece a evolução fisiológica e natural do parto, bem como o exercício do protagonismo e autonomia da mulher, ao proporcionar as sensações de segurança, privacidade e conforto, possibilitando uma vivência mais intensa, humana, afetiva, familiar e pessoal deste processo.

A defesa do parto domiciliar apresenta consonância com a concepção de que o parto e o nascimento fazem parte da natureza e da história de vida humana, assumindo o status de fisiológico e, ao mesmo tempo, de cultural. Assim, parece coerente que o processo de desospitalização e de desmedicalização do parto sejam caminhos a serem vislumbrados, ao passo em que, historicamente, a medicina justificou a institucionalização e a apropriação do parto como objeto da obstetrícia a partir do seu suposto potencial patológico. Cabe, portanto, uma revisão acerca das concepções que definem a gestação, o parto e o nascimento enquanto condições de risco inexorável.

Aponta-se para a necessidade de ampliar o acesso aos Centros de Parto Normal e, a médio e longo prazo, tornar acessíveis os serviços de parto domiciliar também para as parcelas menos favorecidas economicamente, o que poderia ser efetuado através da Estratégia de Saúde da Família, com a observância de estudos que considerem o custo-benefício desta ação. Defende-se a incorporação do parto domiciliar enquanto dispositivo de humanização da assistência e enquanto componente na construção e implementação de um modelo de atenção com um viés holístico, que agregue os elementos positivos de diversos paradigmas e filosofias e valorize o indivíduo inserido em uma coletividade.

Salienta-se que não se sugere o fim das maternidades. Nenhum modelo de atenção que se pretenda eficiente e que respeite os princípios e diretrizes do SUS deve ser inflexível. É necessário humanizar os hospitais, pois é imprescindível que os sujeitos sejam respeitados enquanto cidadãos de direitos independentemente de sua condição de saúde. As gestantes e parturientes que apresentam complicações e distócias também têm o direito ao consentimento informado, de serem tratadas com dignidade e de exercerem a autonomia. Na verdade, apesar de ser sugestionável que as questões de gênero exercem um aprofundamento das relações 
heterônomas, há também uma urgência de mudança mais amplas das concepções, valores e práticas na relação profissional de saúde versus usuário do serviço. Percebe-se, ainda, a forte influencia histórica e ideológica cristalizada na concepção de instituição/hospital/maternidade, que se materializa enquanto um espaço em que é legitimado o controle e a subjugação dos indivíduos. Remete-se para o desafio de elaborar paradigmas, métodos, dispositivos e práticas cotidianas que permitam oferecer subsídios biológicos, ambientais e comportamentais que contribuam para a evolução fisiológica do parto e que garantam o livre exercício da autonomia.

Diante da recorrência do elemento autonomia nos resultados e discussões desta pesquisa, emergiu a demanda de realizar estudos mais específicos que analisem este elemento e suas variáveis expressos no contexto processo de parturição.

É importante deixar claro que este trabalho não pretendeu encerrar questões, mas levantar possibilidades de superação da problemática da assistência ao parto no Brasil, através da descrição de um fenômeno emergente, ainda que ínfimo do ponto de vista quantitativo, considerando também as limitações do tipo de pesquisa bibliográfica e os incentivos insuficientes à produção científica em diversas regiões brasileiras, deficiências que podem mascarar a leitura da realidade.

Deve-se mencionar a necessidade de realizar estudos quantitativos específicos para subsidiar análises situacionais mais fidedignas, já que se sabe da ocorrência de índices consideráveis de subnotificação dos registros de nascidos vivos. Além da elaboração de estratégias para diminuir a subnotificação, cogitamos a possibilidade de serem incluídas nas pesquisas de amplo alcance de órgãos como o IBGE, a exemplo do Senso, perguntas sobre local de ocorrência do nascimento e o tipo de profissional que assistiu ao parto.

Ademais, em consideração à insipiência quantitativa da expressão do parto domiciliar enquanto fenômeno social e ao forte arcabouço ideológico dominante que gera obstáculos objetivos e subjetivos na escolha por esta modalidade, em contraposição aos muitos benefícios e vantagens de sua prática, torna-se importante ampliar a divulgação e o acesso a informações acerca das possibilidades que esta modalidade e que o parto natural oferecem, através dos meios de comunicação de massas, publicação de trabalhos científicos e da ação educativa dos profissionais de saúde. 


\section{REFERÊNCIAS}

1. Davim RMB; Menezes RMP. Assistência ao parto normal no domicílio. Revista LatinoAmericana de Enfermagem. 2001 nov-dez; 9(6):62-8.

2. Moura FMJSP et al. A humanização e a assistência de enfermagem ao parto normal. Rev. bras. enferm. 2007 jul-ago; 60(4):452-45.

3. Brasil. HumanizaSUS: visita aberta e direito a acompanhante. $2^{\mathrm{a}}$ ed. Brasília: Ministério da Saúde; 2007.

4. Brasil. HumanizaSUS: documento base para gestores e trabalhadores do SUS. $3^{\text {a }}$ ed. Brasília: Ministério da Saúde; 2006.

5. GENP. Humanizando o nascimento e o parto: o workshop. In: Rattner D; Trench B, organizadores. Humanizando nascimentos e partos. São Paulo: Editora Senac; 2005. p. 6580 .

6. Souza HR. A arte de nascer em casa: Um olhar antropológico sobre a ética, a estética e a sociabilidade no parto domiciliar contemporâneo [Dissertação de Mestrado]. Florianópolis: Universidade Federal de Santa Catarina, Programa de Pós-graduação em Antropologia Social; 2005.

7. Diniz CSG. Humanização da assistência ao parto no Brasil: os muitos sentidos de um movimento. Ciênc. saúde coletiva. 2005; 10(3):627-37.

8. Acker JIBV, et al. As parteiras e o cuidado com o nascimento. Rev. bras. enferm. 2006 set-out; 59(5): 647-51.

9. Rattner D. ReHuNa: mais de dez anos de uma trajetória luminosa. In: Rattner D, Trench B, organizadores. Humanizando nascimentos e partos. São Paulo: Editora Senac; 2005.

10. Dias JF. O renascimento do parto: Discurso e identidade [Tese de Doutorado em Linguística]. Brasília: Universidade de Brasília; 2007.

11. Brasil. Parto, aborto e puerpério: assistência humanizada à mulher. Brasília: Ministério da Saúde; 2001.

12. Brasil. HumanizaSUS: Política Nacional de Humanização: a humanização como eixo norteador das práticas de atenção e gestão em todas as instâncias do SUS. Brasília: Ministério da Saúde; 2004.

13. Medeiros RMK, Santos IMM, Silva, LRA. A escolha pelo parto domiciliar: História de vida de Mulheres que vivenciaram esta experiência. Revista de Enfermagem. 2008 dez; 12(4):765-762.

14. Barcellos RMG. A infra-estrutura física na humanização do parto. In: Rattner D, Trench B, organizadores. Humanizando nascimentos e partos. São Paulo: Editora Senac; 2005. 
15. Nascimento KC. et al. A arte de partejar: Experiência do cuidado das parteiras tradicionais de Envira/AM. Revista de Enfermagem. 2009 abr-jun; 13(2):319-327.

16 Odent M. A cientificação do amor. São Paulo: Terceira Margem; 2000.

17. Galvão MLS. Memória de ritos e símbolos na prática das parteiras no Nordeste brasileiro. in: Brasil, espaço memória e identidade. In: Lemos MTTB; Bahia LHN; Dembcz A, editores. Warszawa: CESLA; 2001. p. 261.

18. Barreto MR. Assistência ao nascimento na Bahia oitocentista. História, Ciências, Saúde. 2008 out-dez, 15(4): 901-925.

19. Brenes AC. História da Parturição no Brasil, século XIX. Cad. saúde pública. 1991 abrjun; 7(2): 135-49.

20. Del Priore M. Magia e medicina na Colônia: O corpo feminino. In: Del Priore M, organizadora. História das mulheres no Brasil. São Paulo: Contexto; 2006. p. 78-114.

21. Costa T; et al. Naturalização e medicalização do corpo feminino: o controle social por meio da reprodução. Interface comun. saúde educ. 2006 dez; 10(20): 363-80.

22. Foucault M. Microfísica do poder. $14^{\mathrm{a}}$ ed. Rio de Janeiro: Graal; 1999. p. 80.

23. Mott ML. A parteira ignorante, um erro de diagnóstico médico? Revista de Estudos feministas. 1999; 7(1):25-36.

24. Mott ML. Parteiras: o outro lado da profissão. Revista Gênero. $20052^{\circ}$ sem; 6(1):117-40.

25. Weber BT. As artes de curar: Medicina, religião, magia e positivismo na República RioGrandense - 1889-1928. Santa Maria: Editora da UFSM; Bauru: EDUSC; 1999.

26. Barroso IC. Os saberes de parteiras tradicionais e o ofício de partejar em domicílio nas áreas rurais. Revista Eletrônica de Humanidades do Curso de Ciências Sociais da UNIFAP. $2009 \mathrm{dez} ; 2$.

27. Nagahama EEI, Santiago SM. A institucionalização médica do parto no Brasil. Ciênc. saúde coletiva. 2005; 10(3): 651-657.

28. Mott ML. Fiscalização e a formação de parteiras em São Paulo. (1880-1920). Rev. Esc. Enferm. USP. 2001 mar; 35(1):46-53.

29. Helman CG. Cultura, Saúde e Doença. Porto Alegre (RS): ARTMED; 2003 apud Acker JIBV et al. As parteiras e o cuidado com o nascimento. Rev. bras. enferm. 2006 set-out; 59(5): 647-51.

30. Wolff LR; Waldow VR. Violência consentida: mulheres em trabalho de parto e parto. Saúde soc. 2008 jul-set; 17(3):138-51.

31. Previatti JF; Souza KV. Episiotomia: em foco a visão das mulheres. Rev. bras. enferm. 2007 abr; 60(2):197-201. 
32. Crizóstomo CD; Nery IS; Luz MHB. Vivência de mulheres no parto domiciliar e hospitalar. Escola Anna Nery, Revista de Enfermagem. 2007 mar; 11(1): 98-104.

33. Kruno RB. Parto domiciliar na voz das mulheres: uma perspectiva à luz da humanização [Dissertação de Mestrado em Enfermagem]. Porto Alegre: Universidade Federal do Rio Grande do Sul; 2004.

34. Benevides R, Passos E. A humanização como dimensão pública das políticas de saúde. Ciênc. saúde coletiva. 2005 set, 10(3): 561-571.

35. Tornquist CS. Parteiras populares: entre o folclore e a escuta. Rev. Gênero. $20052^{\circ}$ sem, 6(1): 61-80.

36. Salém T. Sobre o casal grávido: Incursão em um universo ético. [Tese de Doutorado] Rio de Janeiro: Museu Nacional, Universidade Federal do Rio de Janeiro; 1987 apud Souza HR. A arte de nascer em casa: Um olhar antropológico sobre a ética, a estética e a sociabilidade no parto domiciliar contemporâneo [Dissertação de Mestrado]. Florianópolis: Universidade Federal de Santa Catarina, Programa de Pós-graduação em Antropologia Social; 2005.

37. Leboyer F. Nascer Sorrindo. São Paulo: Editora Brasiliense; 1974.

38. Odent M. O renascimento do parto. Florianópolis: Saint Germain; 2002.

39. Brasil. Parto e nascimento domiciliar assistidos por parteiras tradicionais: O Programa Trabalhando com Parteiras Tradicionais e experiências exemplares. Brasília: Ministério da Saúde; 2010.

40. Osis MJD Paism: Um Marco na Abordagem da Saúde Reprodutiva no Brasil. Cad. saúde pública. 1998; 14(Supl. 1):25-32.

41. Brasil. Política nacional de atenção integral à saúde da mulher: princípios e diretrizes. Brasília: Ministério da Saúde; 2009.

42. Brasil. Assistência Integral à Saúde da Mulher: bases de ação programática. Brasília: Ministério da Saúde; 1984.

43. Brasil. Ministério da Saúde. Portaria n. 163, de 22 de setembro de 1998. Trata das atribuições do enfermeiro obstetra e da obstetriz. Diário Oficial da União. 1998 set.

44. Brasil. Ministério da Saúde. Portaria n. 888/GM, de 12 de julho de 1999. Institui o Projeto Casas de Parto e Maternidades Modelo. Brasília; 1999. Disponível em: <http:// www.saude.gov.br/>.

45. Brasil. Ministério da Saúde. Portaria n. 985/GM, de 05 de agosto de 1999. Estabelece critérios para criar o Centro de Parto Normal - CPN no âmbito do SUS. Brasília; 1999. Disponível em: <http://www.saude.gov.br/>.

46. Gil AC. Métodos e técnicas de pesquisa social. $5^{\text {a }}$ ed. São Paulo: Atlas; 1999.

47. Marconi MA; Lakatos EM. Técnicas de pesquisa. 5a ed. São Paulo: Atlas; 2002. 
48. Polit DF; Beck CT; Hungler BP. Fundamentos de pesquisa em enfermagem: métodos, avaliação e utilização. Porto Alegre: Artmed; 2004.

49. Minayo MCS. O desafio do conhecimento: pesquisa qualitativa em saúde. $6^{a}$ ed. São Paulo: Hucitec; Rio de Janeiro: Abrasco; 1999.

50. Ferreira ABH. Novo dicionário Aurélio da língua portuguesa. $4^{\mathrm{a}}$ ed. Ferreira MB; Anjos M, coordenadores. Curitiba: Positivo; 2009.

51. Instituto Brasileiro de Geografia e Estatística. Estatísticas do Registro Civil. Rio de Janeiro. 2009; 36:1-186.

52. Instituto Brasileiro de Geografia e Estatística. Síntese de indicadores sociais: Uma análise das condições de vida da população brasileira 2010. Estudos e Pesquisas, Informação Demográfica e Socioeconômica. Rio de Janeiro; 2010.

53. Brasil. Pesquisa Nacional de Demografia e Saúde da Criança e da Mulher - PNDS 2006: dimensões do processo reprodutivo e da saúde da criança. Brasília: Ministério da Saúde; Centro Brasileiro de Análise e Planejamento; 2009.

54. Borges MS; Pinho DLM; Santos SM. As representações sociais das parteiras tradicionais e o seu modo de cuidar. Caderno Cedes, 2009 set-dez; 29(79): 373-385.

55. Pinto BCM. Vivências cotidianas de parteiras e 'experientes' do Tocantins. Revista de Estudos Feministas. 2002; 10(2):441-8.

56. Batista AP. O saber e o fazer das parteiras tradicionais: aprendizagens perpetuadas no espaço doméstico. [Dissertação de Mestrado em Educação] Petrópolis: Universidade Católica de Petrópolis; 2010.

57. Dias MD. Histórias de vida: as parteiras tradicionais e o nascimento em casa. Rev. eletrônica enferm. 2007; 9(2):476-488.

58. Aires MJ. Técnica e tecnologia do parto: produção e apropriação do conhecimento tecnológico por parteiras tradicionais. [Dissertação de Mestrado em Tecnologia] Curitiba: Universidade Federal Tecnológica do Paraná; 2006.

59. Fleischer S. Então, minha filha, vamos se afomentar? Puxação, parteiras e reprodução em Melgaço, Pará. Ciênc. saúde coletiva. 2008; 13(3):889-98.

60. Fleischer SR. Parteiras, buchudas e aperreios: Uma etnografia do atendimento obstétrico não oficial na cidade de Melgaço, Pará. [Tese de Doutorado em Antropologia Social] Porto Alegre: Universidade Federal do Rio Grande do Sul; 2007.

61. Borges MS; Pinho DLM.; Guilhen DA construção do cuidado das parteiras tradicionais: um saber/fazer edificante. Rev. bras. enferm. 2007 maio-jun; 60(3): 317-322.

62. Brasil. Ministério da Saúde. Secretaria de Ciência, Tecnologia e Insumos Estratégicos. Departamento de Ciência e Tecnologia. PNDS 2006: Pesquisa Nacional de Demografia e Saúde da Criança e da Mulher: relatório. Brasília; 2008 apud Brasil. Parto e nascimento 
domiciliar assistidos por parteiras tradicionais: O Programa Trabalhando com Parteiras Tradicionais e experiências exemplares. Brasília: Ministério da Saúde; 2010.

63. Kruno, RB, Bonilha AAL. Parto domiciliar na voz das mulheres: uma perspectiva à luz da humanização. Rev. gaúch. enferm. 2004 dez; 25(3):396-407.

64. Koettker JG. et al. Hanami: O Florescer da Vida: Enfermeiras no atendimento ao parto domiciliar planejado. [data desconhecida]. Disponível em:

<http://www.furb.br/formularios/aleitamento/anais/ots/art_ots_03.pdf>

65. Santos ML. Humanização da assistência ao parto e nascimento: Um modelo teórico [Dissertação de Mestrado em Saúde Pública] Florianópolis: Universidade Federal de Santa Catarina, Programa de Pós-Graduação em Saúde Pública; 2002.

66. Riesco MLG, Fonseca RMGS. Elementos constitutivos da formação e inserção de profissionais não-médicos na assistência ao parto. Cad. saúde pública. 2002 maio-jun; 18(3):685-98.

67. Osava RH, Tsunechiro MA, Saito E. A contribuição da enfermagem na promoção do parto natural. Revista Conexão SEESP. 2010 mar-abr; 29:01-04.

68. Medeiros H. O parto fora da maternidade. Revista Tudo sobre Parto. 1986 dez; 1: 20-3 apud Davim RMB; Menezes RMP. Assistência ao parto normal no domicílio. Revista Latino-Americana de Enfermagem. 2001 nov-dez; 9(6):6 